\title{
السلطات الموسعة للشرطة القضائية في جرائم المخدرات
}

The expanded powers of the judicial police for drug crimes

تاريخ الاستلام : 2020/02/26؛ تاريخ القبول : 2020/08/09

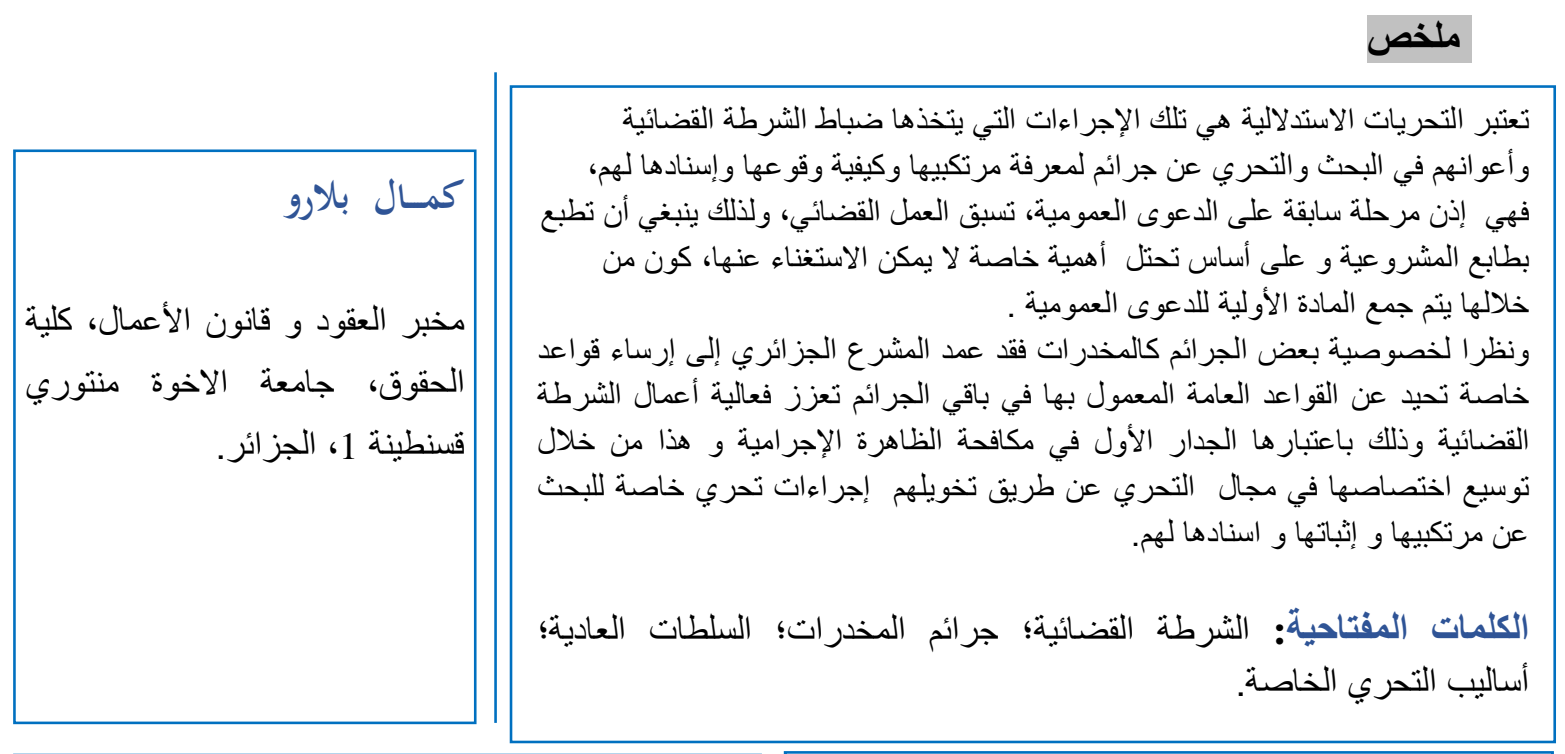

\section{Abstract}

The inferential or preliminary investigations stage means those measures that the judicial police officers and their agents take in searching and investigating crimes to find out the perpetrators and how it occurred and attribute it to them. It is a stage prior to a public lawsuit and therefore it is a precedent for judicial work, and therefore it should be legitimate, because of that it should not be exercised by those who were not empowered by law to perform it, just as it is not permissible for judicial police officers and their agents exceeding the limits of the powers assigned to them and obliged to use legitimate means.

and he initial investigation stage occupies a special importance that it is the stage on which all phases of the public.

Keywords: judicial police ; drug crimes ; ordinary powers ; special investigative techniques.

\section{Résumé}

L'étape des enquêtes déductives ou préliminaires désigne les mesures que les officiers de police judiciaire et leurs agents prennent pour rechercher et enquêter sur les délits afin de découvrir les auteurs et comment ils se sont produits et de les attribuer. Il s'agit d'une étape antérieure à un procès public et, par conséquent, c'est un précédent pour le travail judiciaire, et donc il devrait être légitime, car il ne devrait pas être exercé par ceux qui n'étaient pas habilités par la loi à l'exécuter, tout comme il est pas autorisé pour les officiers de police judiciaire et leurs agents dépassant les limites des pouvoirs qui leur sont attribués et obligés d'utiliser des moyens légitimes.

autorisés à inspecter ces délits, soit en élargissant la juridiction régionale du police.

Mots clés: police judiciaire ; délits liés à la drogue ; pouvoirs ordinaires ; techniques d'enquête spéciales.

* Corresponding author, e-mail: bellaroukamel@gmail.com 


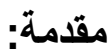

يقصد بالمرحلة الاستدلالية او التحريات الاولية هي تلك الإجراءات التي يتخذها

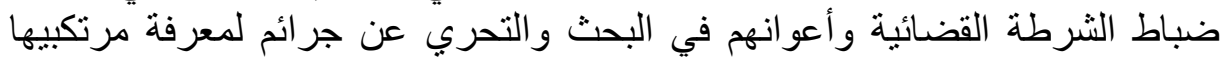

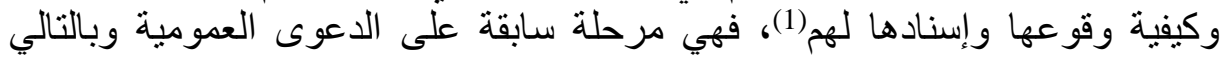

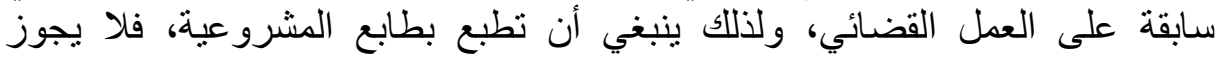

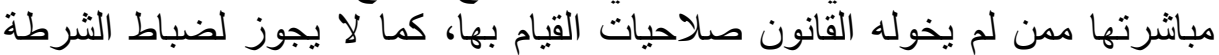

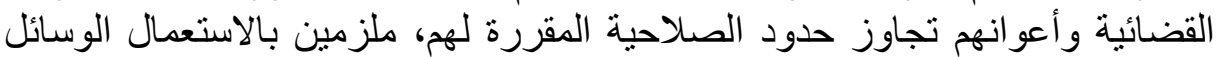

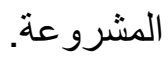

وتحتل مرحلة التحريات الاولية أهمية خاصة من حيث أنها الأساس التي تقوم عليه

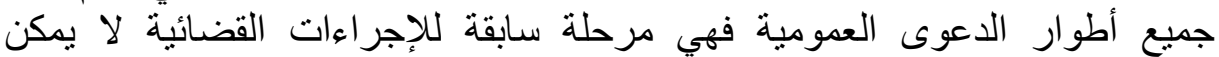

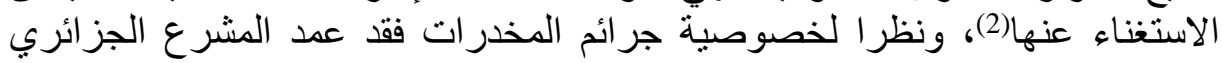

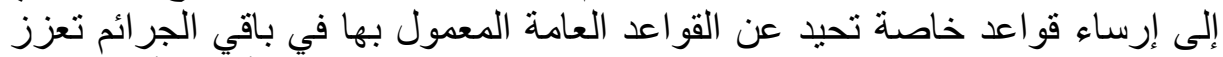
نشاط الثرطة القضائية من حيث عناصرهاء اعتا وتوسيع اختصاصها أثناء تأدية المهام

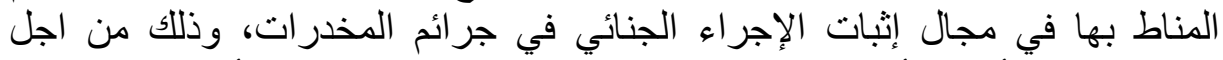

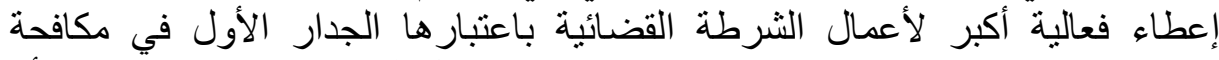

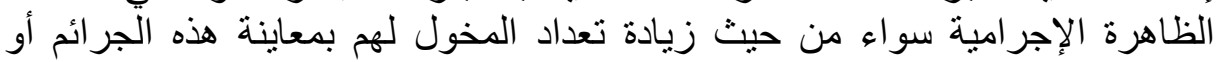

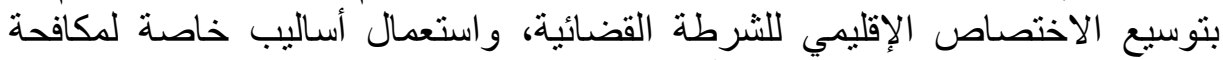

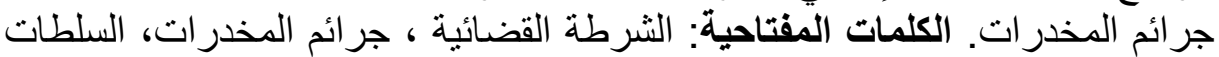
العادية ، اساليب التحري الخاصة.

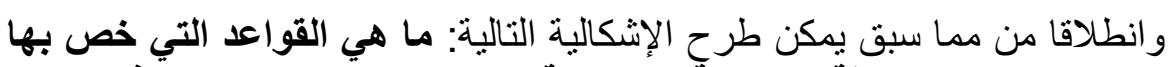

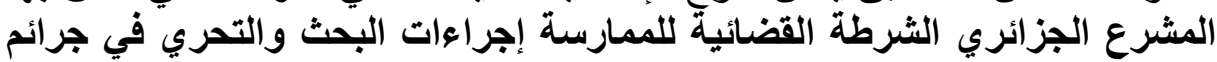
المخدرات، وما مدى فعاليتها في الحد من هذه الظاهرة المّلة الإجراميةّ؟.

وللإجابة على هذه الإشكالية لابد من تقسيم موضوع هذه المداخلة إلى مبحثين،

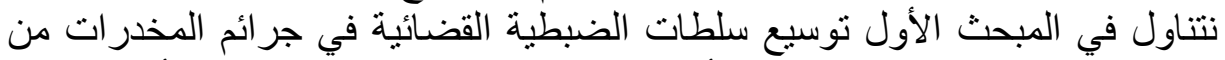

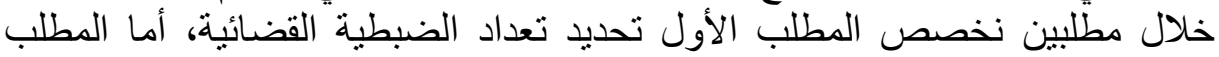
الثاني نفرده لدر اسة تعزيز صلاحيات التحري للشرطة التصني القضائية.

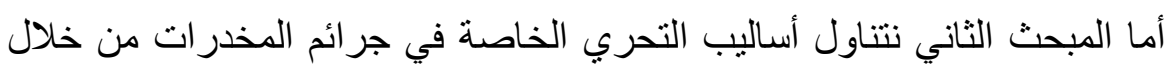

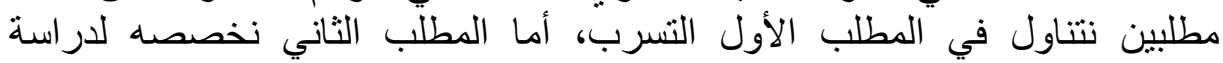

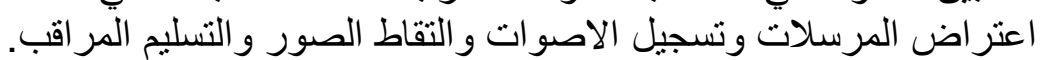

ونتهي المداخلة بالخاتمة تتضمن أهم النتائج والتوصيات التي توصلنا إليها من

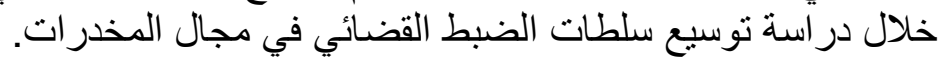
المبحث الأول :توسيع سلطات الثرطة القضائية في جرائم المخدرات

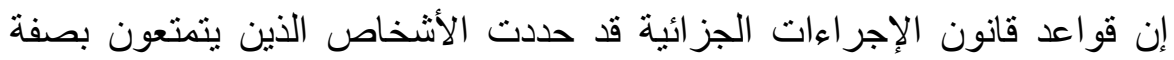

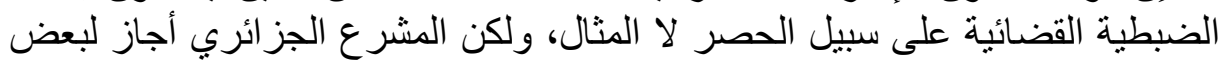

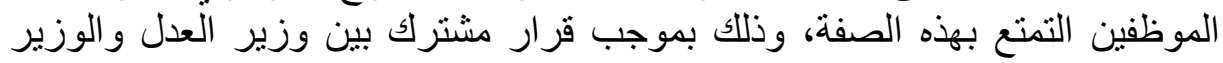

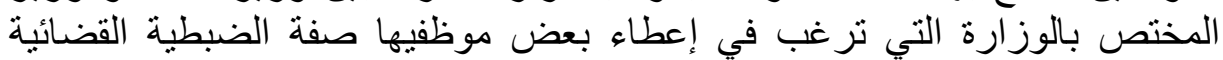
وذلك بالنسبة للجر ائم التي تقع في دائرة عملهم وتكون متعلقة بأعمال وظائفهر. 


\section{المطلب الأول: أعضاء الضبط القضائي}

تشمل الضبطية القضائية ضباط الثرطة القضائية التي تمنح لهم هذه الصفة الصنة

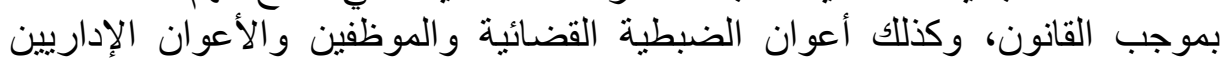

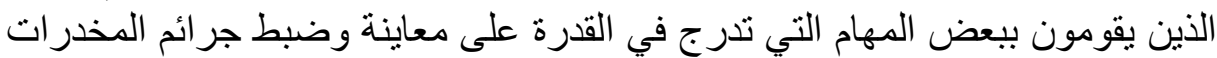
و المؤثرات العقلية على هذا الأساس سنحاول تحديد فئات الضبطية القضائية على الفي الني النحو التالي: - (الت

\section{الفرع الأول :ضباط وأعوان الثرطة القضائية}

أولا- ضباط الثرطة القضائية: وهذا حسب ما هو محدد بموجب المادة 15 من من 15 من

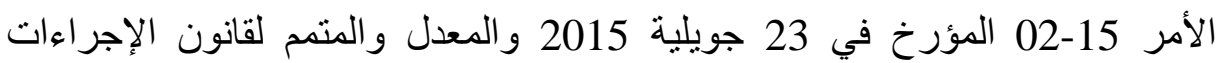

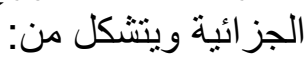

- رؤساء المجالس الثعبية البلدية.

$$
\text { - ضباط الدرك الوطني. }
$$

ـ الموظفين التابعين للأسلاك الخاصة للمر اقبين ومحافظي وضباط الشرطة للأمن

حيث يتمتع من يشغل هذه الوظيفة على صفة ضابط شرطة قضائية بموجب

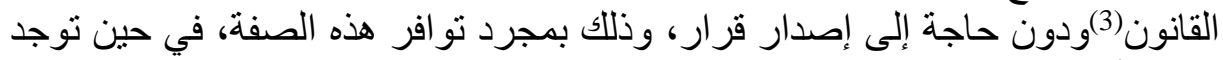

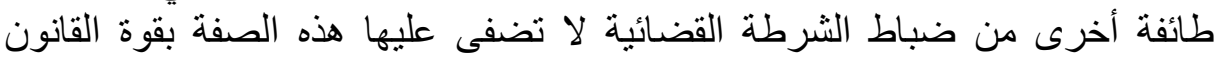

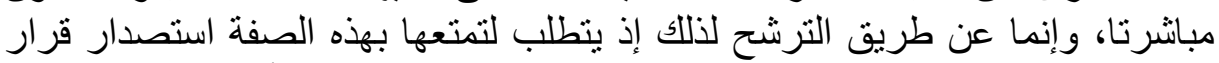

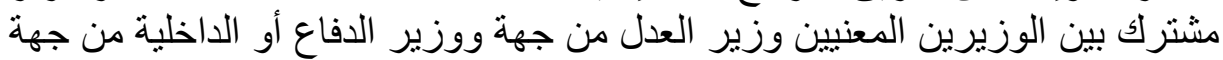

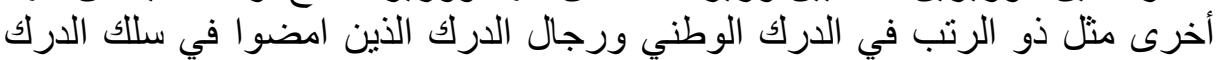

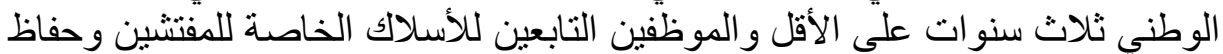

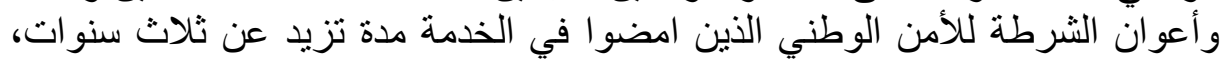

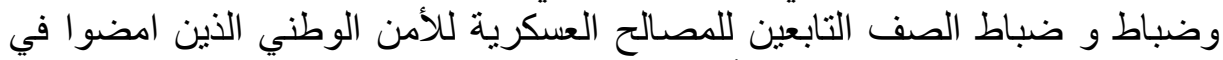

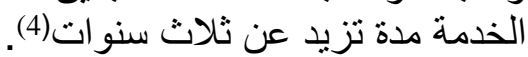

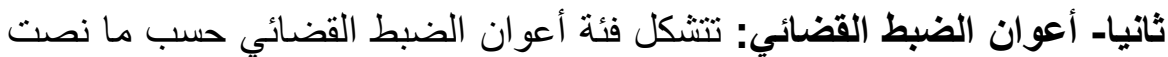

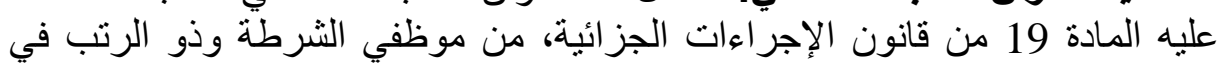

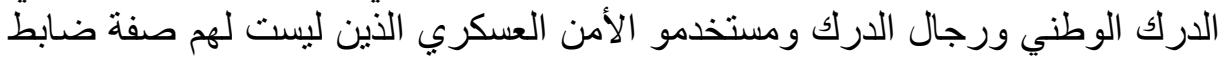
الثرطة القضائية.

وتتلخص مهام أعوان الثرطة القضائية التي تضمنتها المادة 20 من قانون

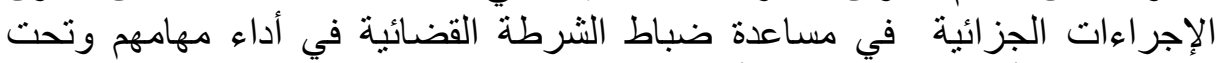

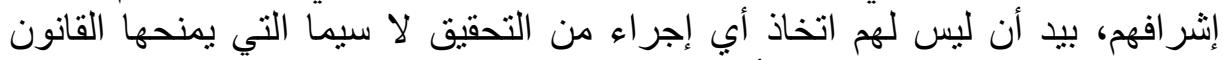

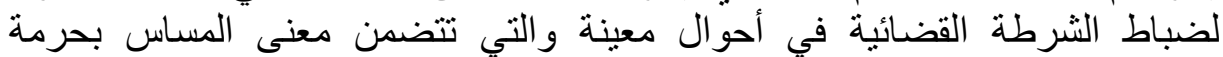

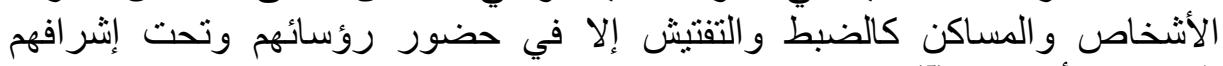
المباشر وبأمر منهم(5). - (5).

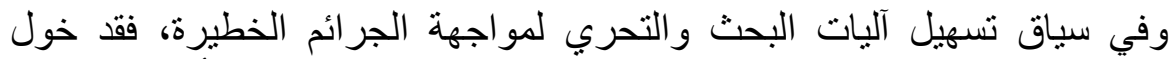

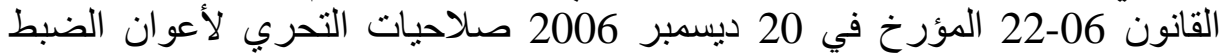

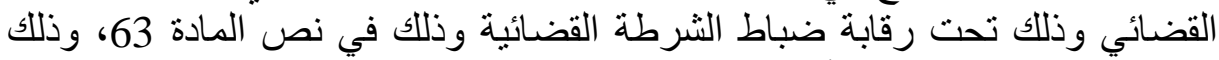
في إطار تعزيز صلاحيات أعوان الضبط القضائي نكان. 
القرع الثاني: الموظفون المؤهلون بمعاينة جرائم المخدرات

لم يجعل المشرع الجزائري صفة الضبطية القضائية محصورة في يد ضباط النهاط

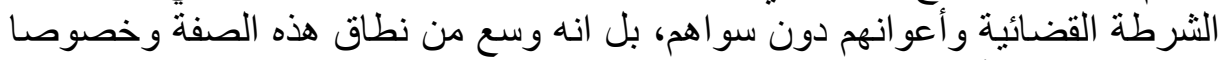

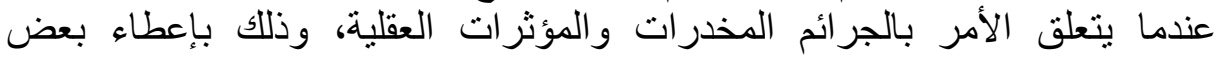

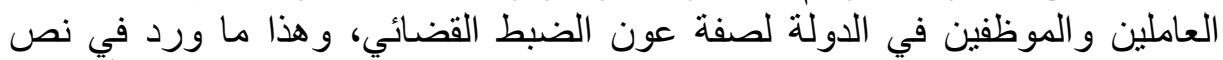

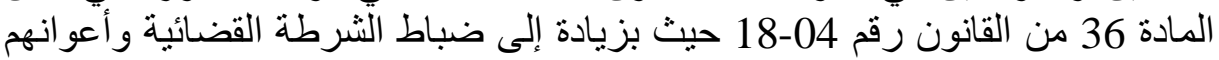

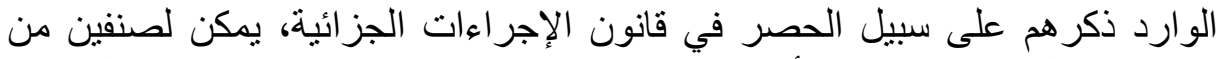

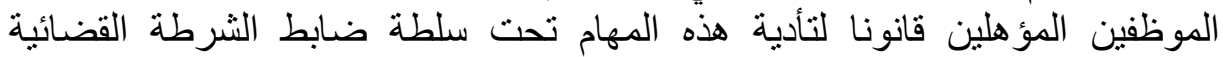
بالبحث عن الجرائم المنصوص عليها في القانون 04-18 وهما:

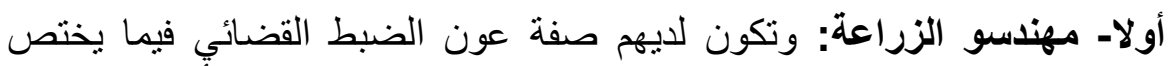

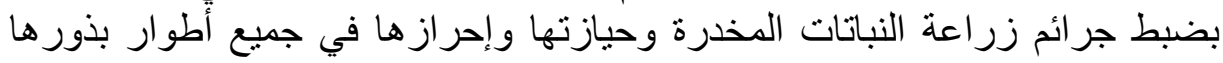
ونمو ها.

ثانيا- مفتشو الصيدلة: وذلك عندما يتعلق الأمر بضبط الجرائم المتعلقة

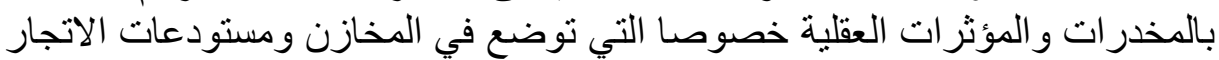

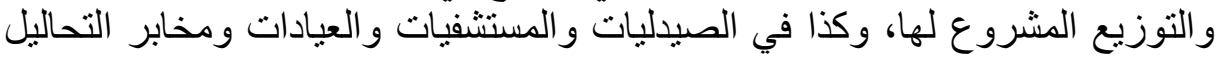

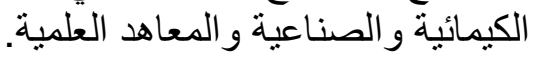

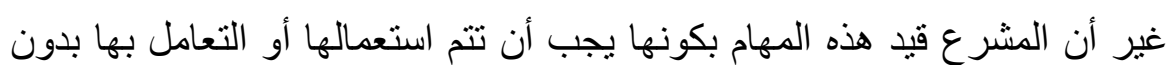

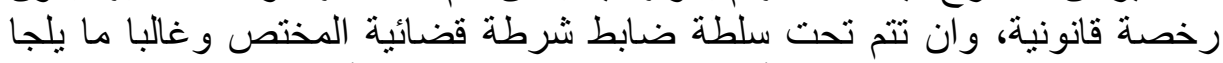

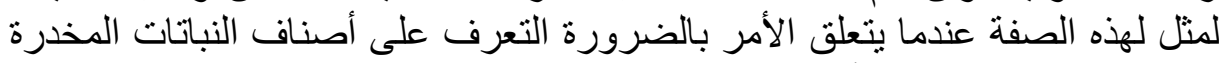

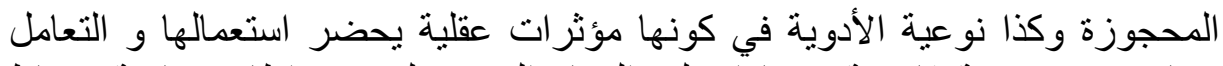

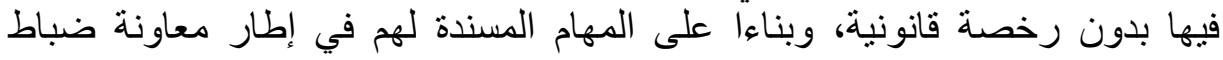

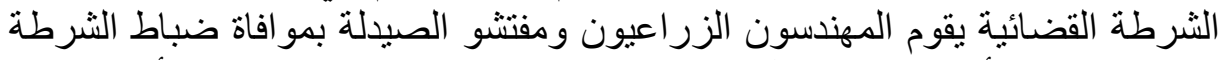

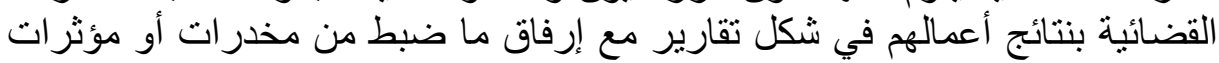

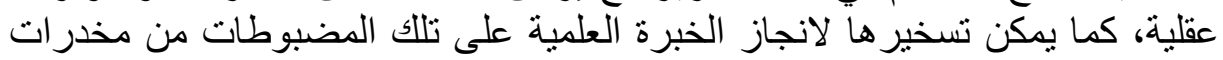
ومؤثرات عقلية وذللك على مستوى الجهات القضئيائة(7).

\section{المطلب الثاني: تعزيز صلاحيات التحري للشرطة القضائية}

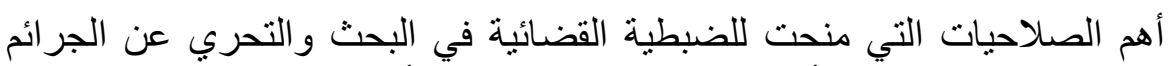

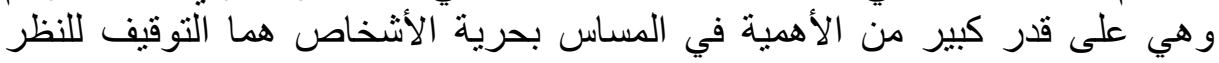

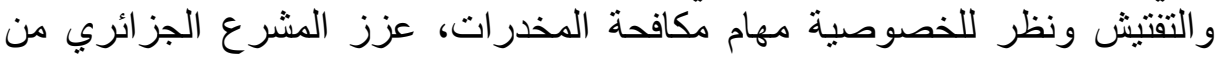

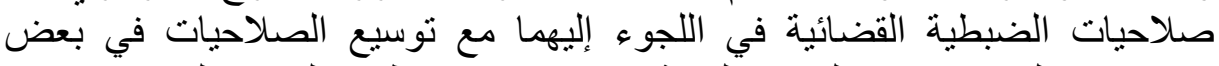

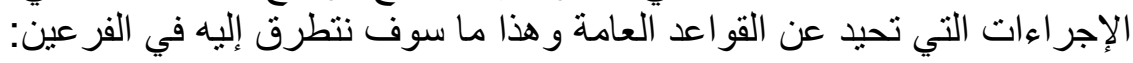

\section{الفرع الأول: تمديد الاختصاص الإقليمي}

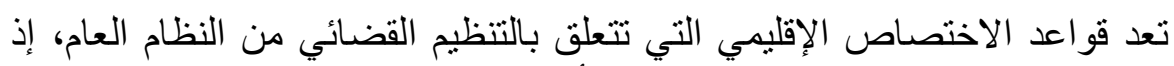

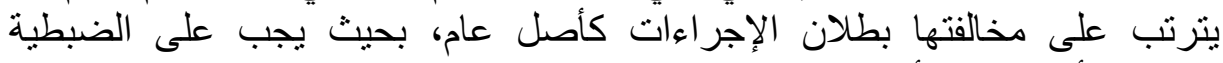

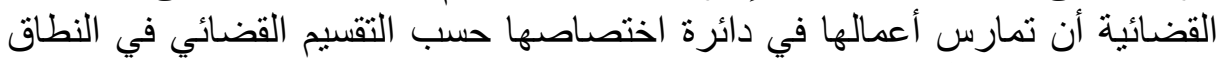
الإقليمي و الدو ائر التابعين لهارسانئ.

وون اجل ضمان نجاعة وفعالية النصوص الإجرائية الجزائية وجعلها أكثر ملائمة

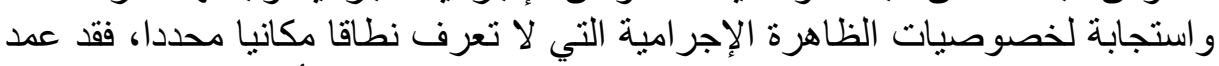

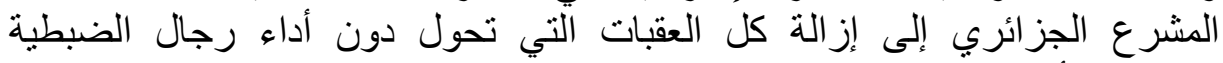

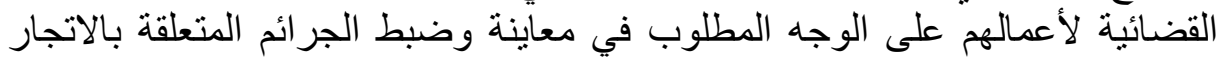


بالمخدرات والمؤثرات العقلية، حيث تم تعديل نص المادة 16 من قانون الإجراءات الجزائية بموجب القانون 22-06 الذي أضاف فقرة إلى نص المادة السالفة الذكر، الذاني

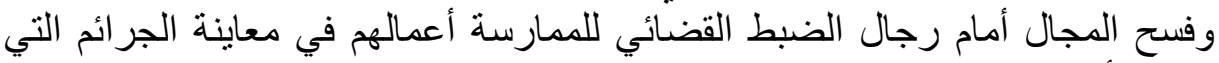

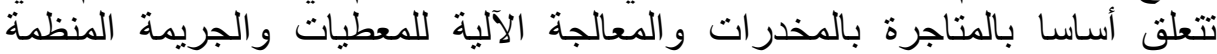

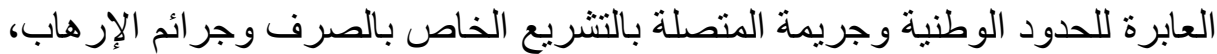

حيث يمتد اختصاص الضبطية القضائية إلى كامل اقلين التراب التُبن الوطني(9).

\section{الفرع الثاني: تمديد مدة التوقيف للنظر}

لقد وسع المشرع الجزائري من اختصاص الضبطية القضائية في حالة ما إذا كان

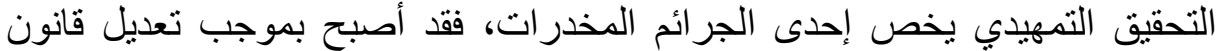
الإجراءات الجزائية 20 ديسمبر 2006، وكذا قانون الوقاية من المخدرات وات والمؤثر ات

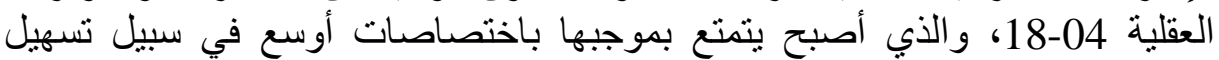

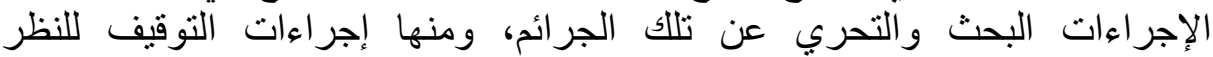
والاستثناءات الواردة بشان تمديده على النحو التالي:

\section{أولا- تعريف التوقيف للنظر:}

هو إجراء بوليسي ينفذه بأمر من ضابط الشرطة القضائية لضرورة التحري

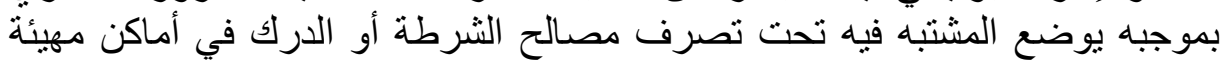

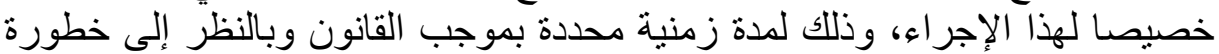

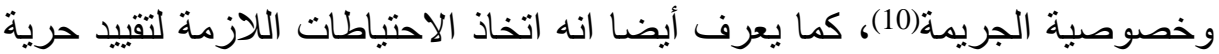

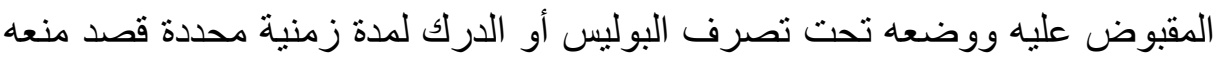

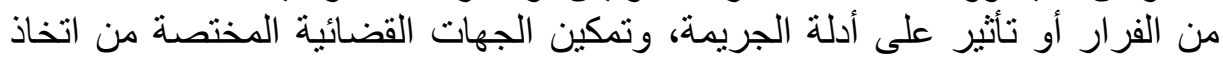

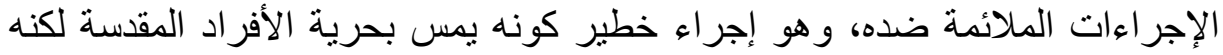

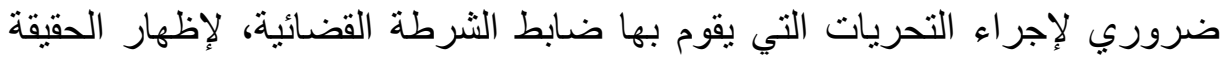

ومعرفة ملابسات الجريمة ومرتكبي الجر ائم(11).

وتجسيدا لمبدأ الشرعية الإجرائية ونظر الأهمية القصوى فقد نص عليه الديه الدانتور

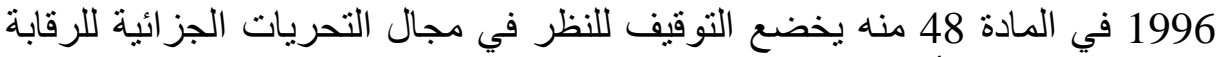

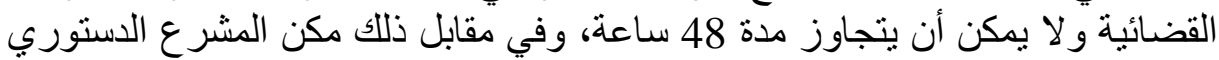

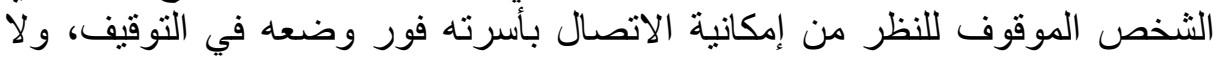

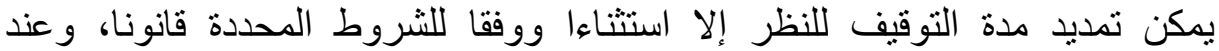

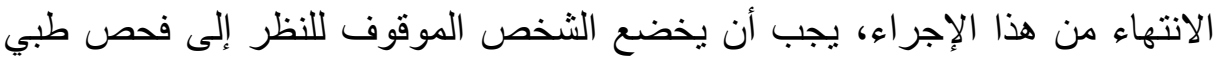

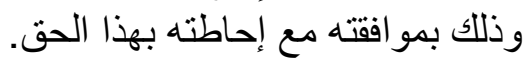

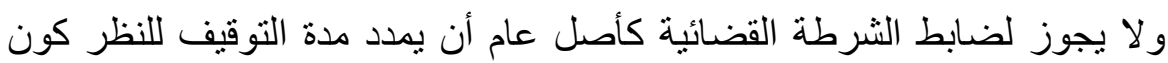

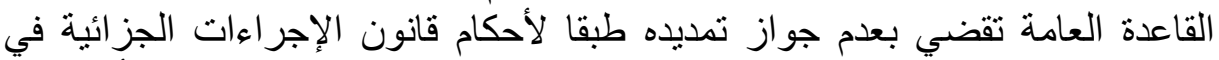

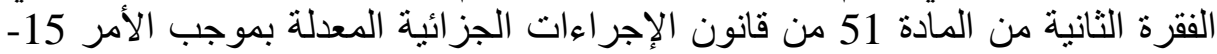

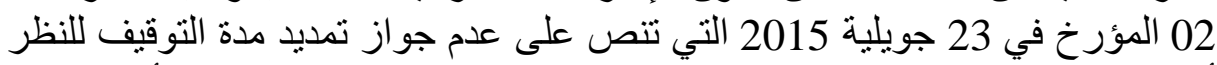

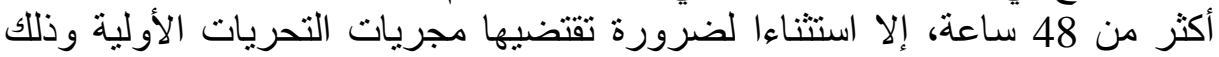
وفقا للمادة 48 من الدستور الجزائري التي تتيح تمديد مدة التوقيف للنظر إذا كانت ضرورية في الكثف عن هوية المجرمين.

\section{ثانيا- الحالات الاستثنائية الواردة على تمديد التوقيف للنظر:}

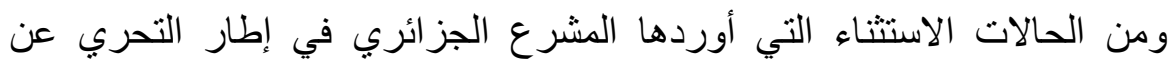

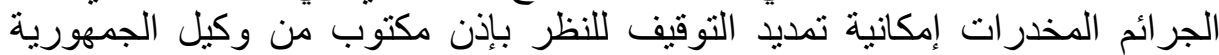

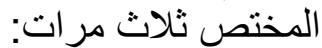


1- في إطار التحري عن الجريمة المتلبس بها: المنصوص عليها في الفقرة الثانية

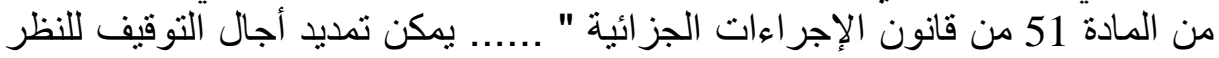

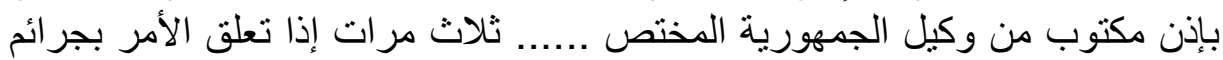

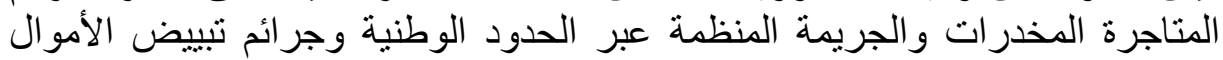
و الجر ائم المتعلقة بالتشريع الصرف الصرف ".

2- في حالة التحقيق الابتدائي: تنص المادة 37 من القانون 04-18 على انه " لإندانه

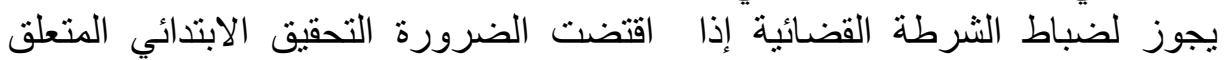

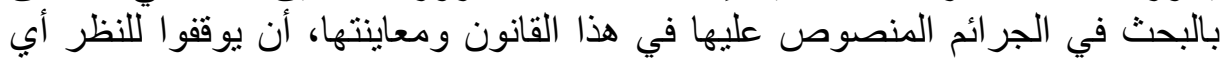

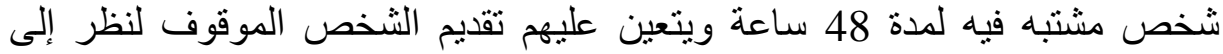

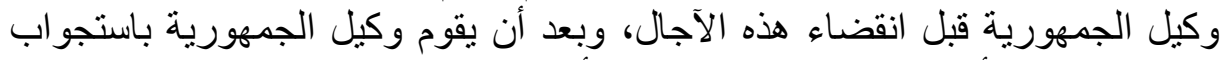

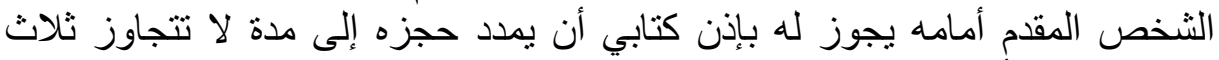

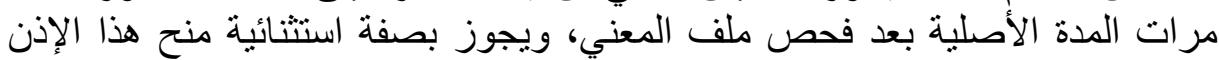

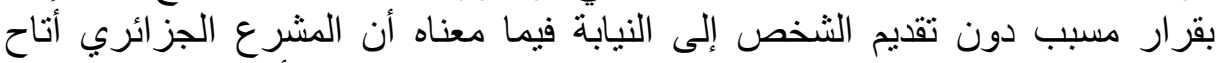

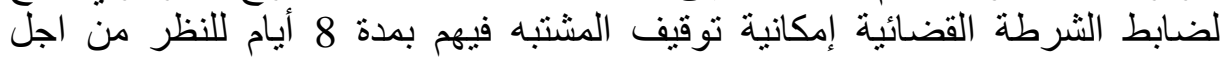
التحري في الجرائم المخدر ات كما في حالة التلبس.

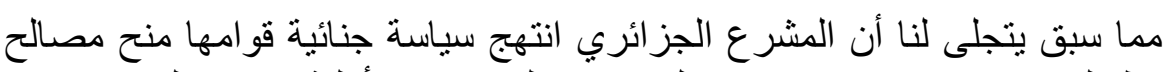

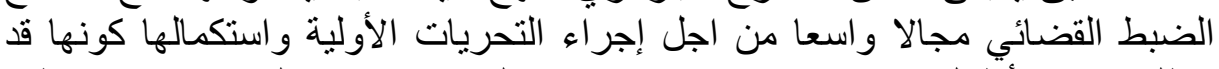

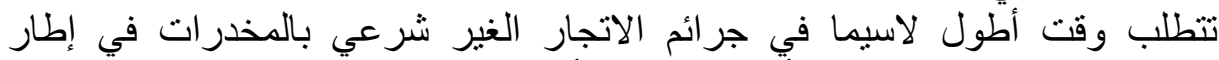

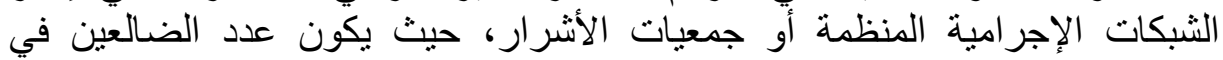

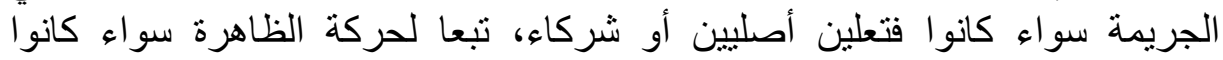

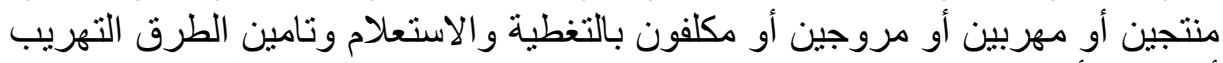

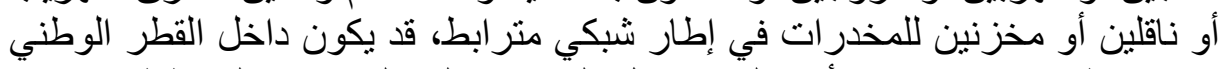

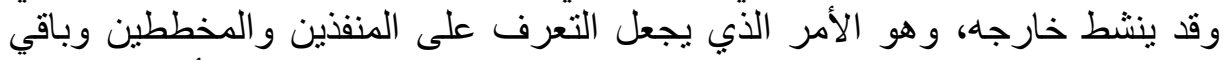

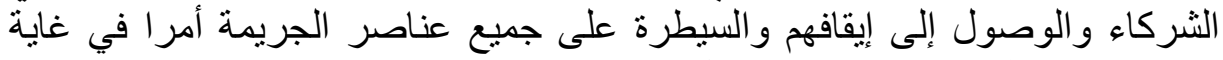

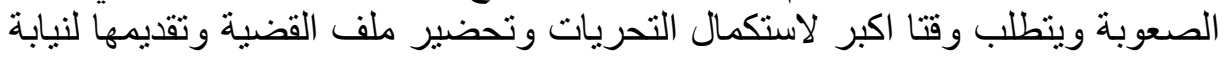

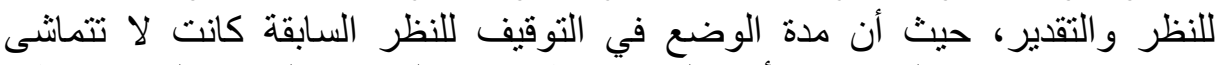

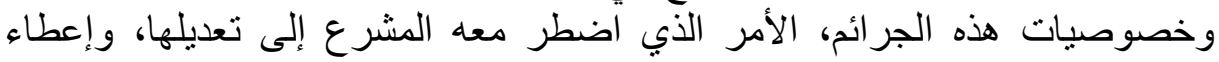

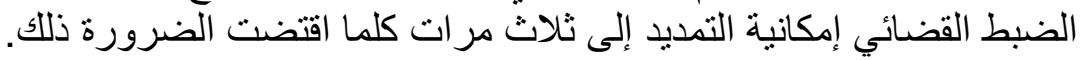

\section{الفرع الثالث :إقرار نظام التفتيش}

التفتيش لغتا هو البحث والاستقصاء، أما قانونا فهو الاضطلاع على على محل كفله

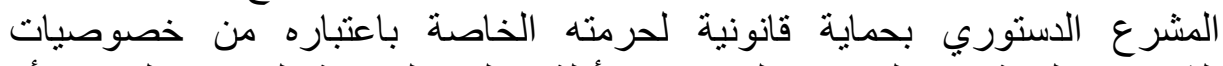

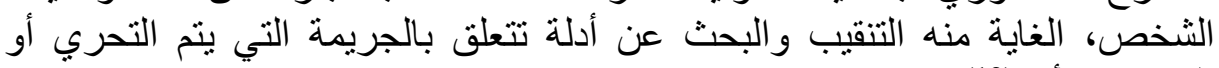
التحقيق بشأنها(12).

ويعد إجراء التفتيش من اخطر الإجراءات التي منحت للمحقق كونها تطال الحرية

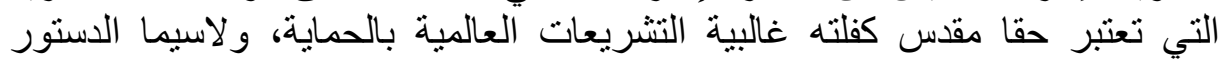

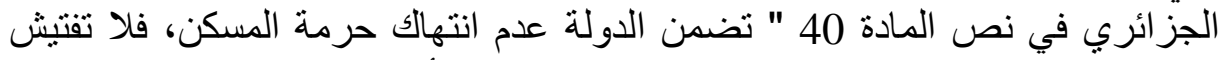

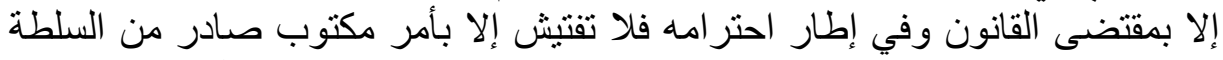

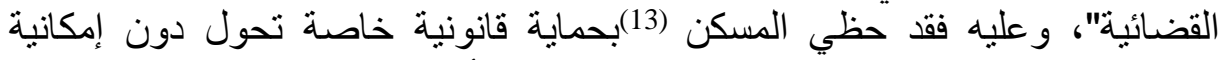

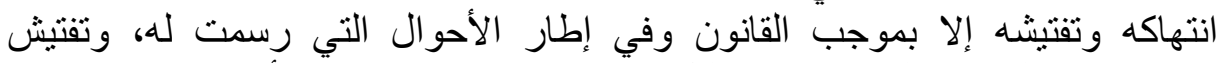

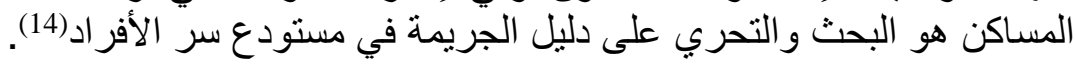




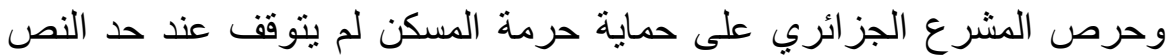

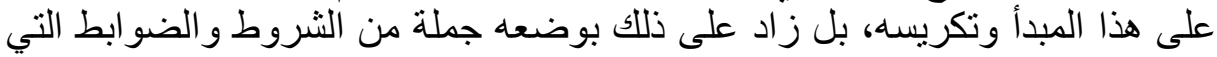

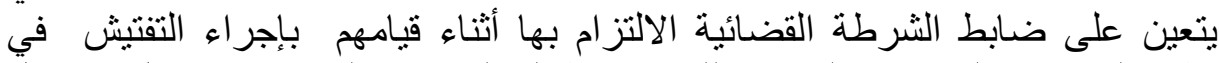

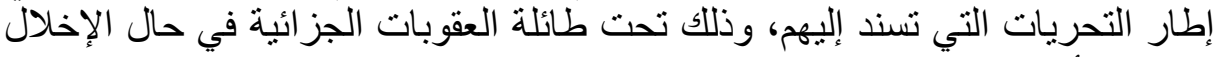

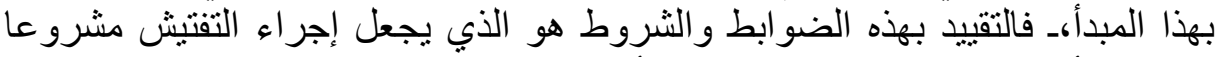

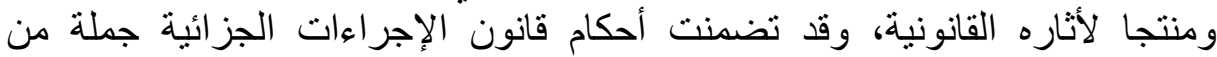

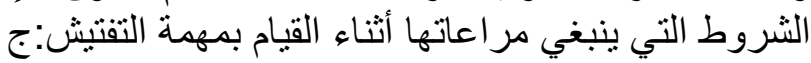

- شرط المكان: بحيث يقتضي إجر اء التفتيش إلا على مسكن المشتبه في ارتكابه

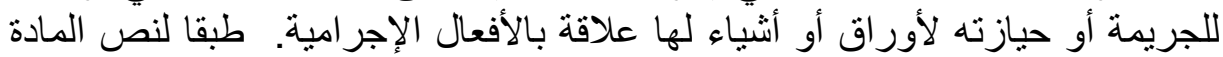

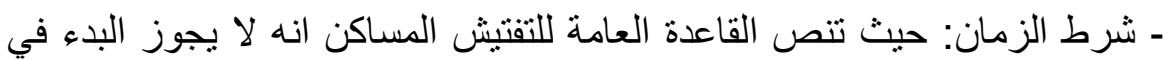

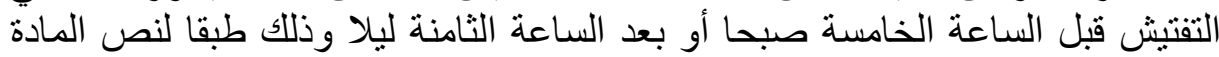
47 من ق الم: ج.

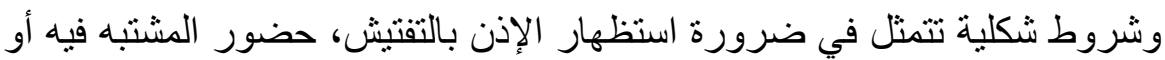

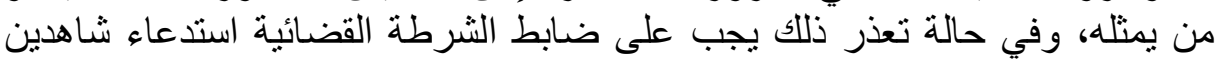

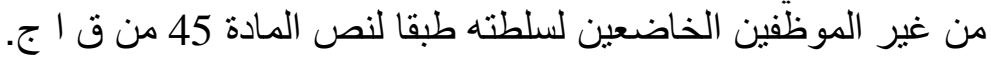
غير انه ولدواعي الضرورة الملحة التي تستلزمها مصلحة المجتمع في القضاء

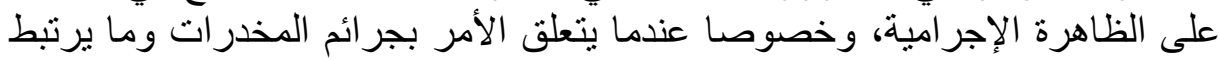

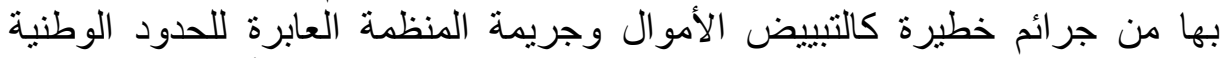

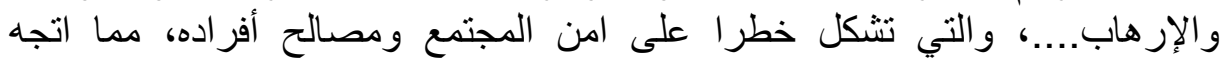

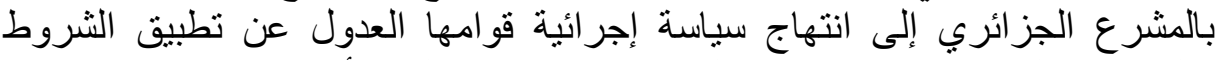

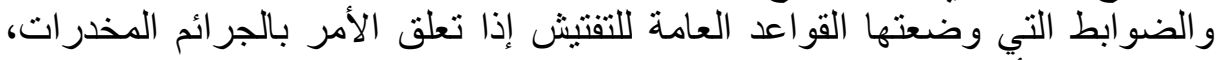

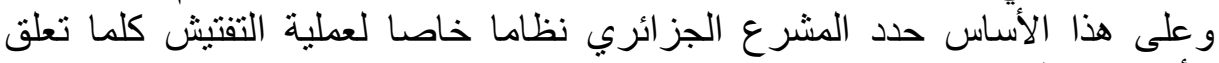

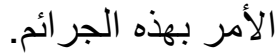

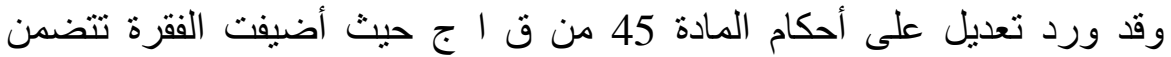

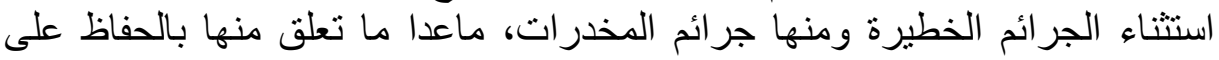

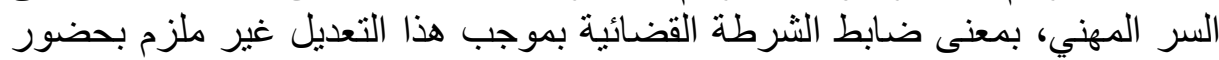

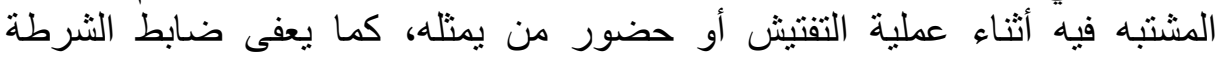

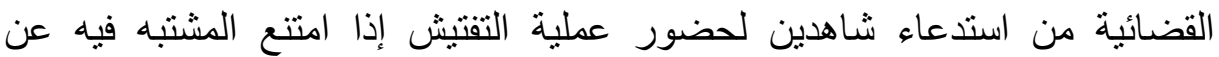
حضور أو كان هاربا.

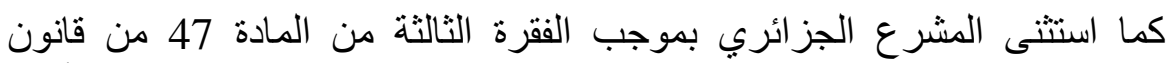

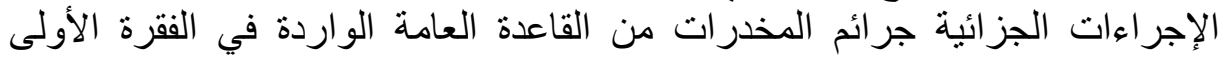

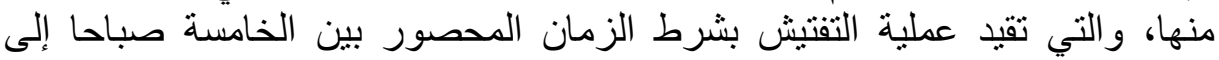

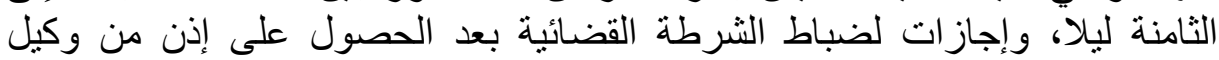

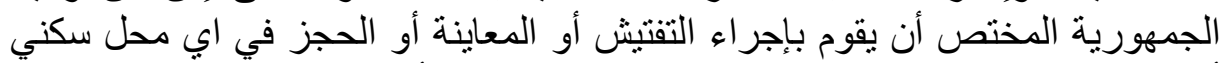

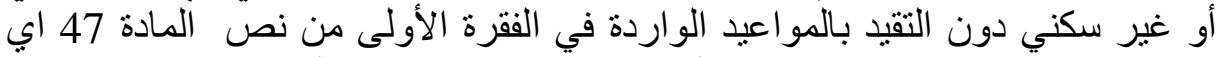
انه يجوز لضباط الثرطة تفتيش في أي ساعة من ساعات الليل أو النهار.

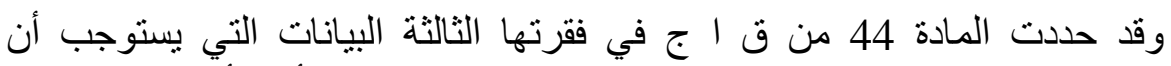

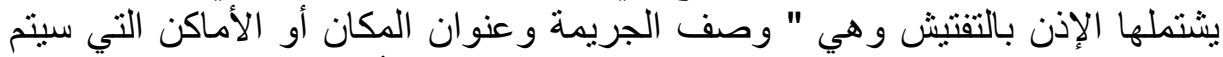

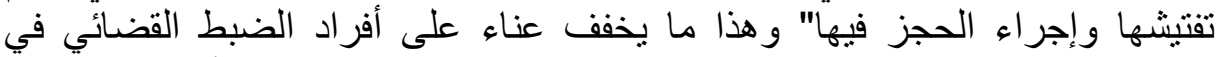
البحث عن الهوية الكاملة للمشتبه فيهم الذين يلجاءواءون إلهاء إلى استعمال أسماء مستعارة بهدف التمويه، والذي كان يعرض عملية البحث والتحري إلى الفنى الفي ومن تم عدم 
التمكن من ضبطهم، و هي خطة عامة اعتمدها المشرع ليس إلا في الجرائم المخدرات

ويهدف المشرع الجزائي من وراء هذه الإجراءات إلى رفع القيود وإزالة العقبات

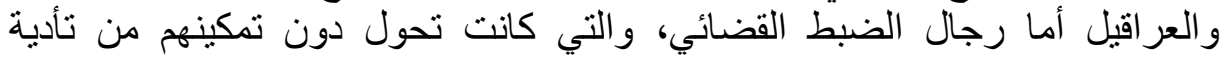

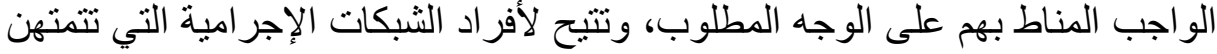

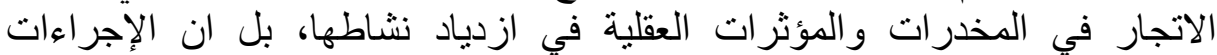

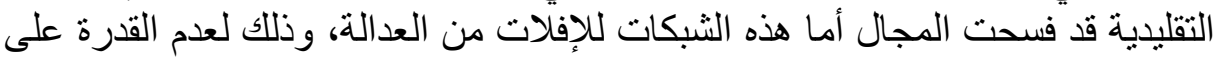
ضبط أنشطتها وتوقيفها و إقامة الدليل على تورطها ومن نم إعاقة ظهور الحقيقة وتظليل العدالة الجنائية.

\section{المبحث الثاني: أساليب التحري الخاصة في جرائم المخدرات}

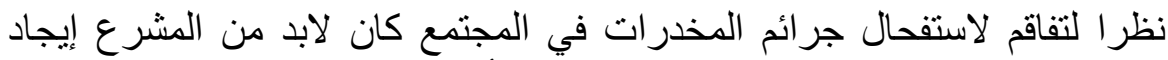

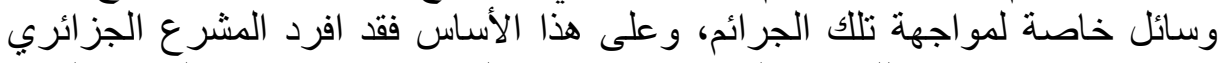

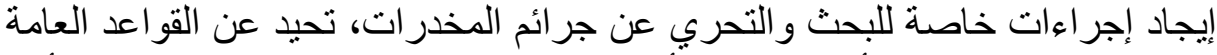

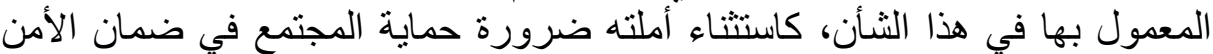

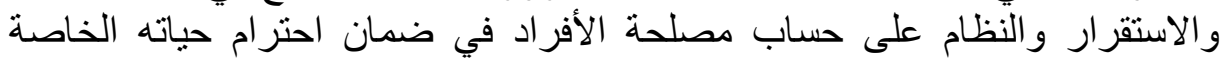
بهدف تضييق الخناق على جرائم الاتجار الغير مشروع الألى بالمخدرات.

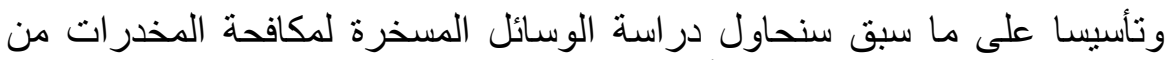

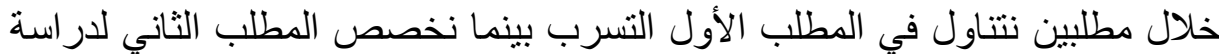
اعتر اض المر اسلات وتسجيل الأصوات فلات والتقاط الصور

$$
\text { المطلب الأول: التسرب التراب }
$$

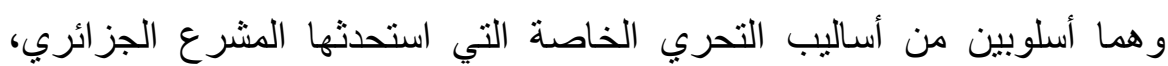

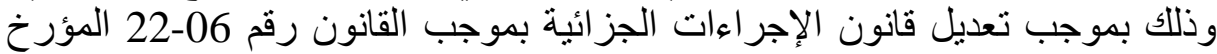

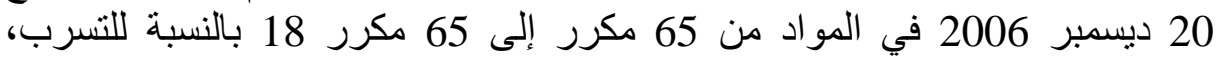

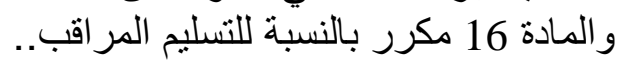

فقد نصت المادة 65 مكرر 11 على انه عندما تقتضي ضرورة التهرة التحري أو التحقيق

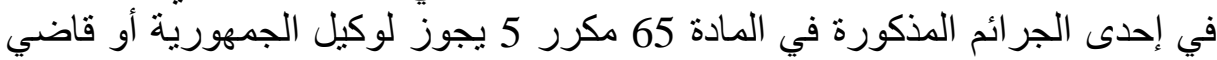

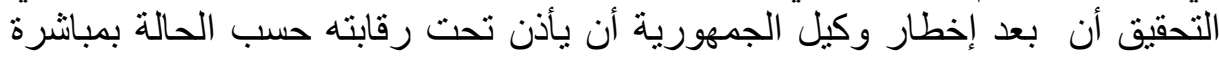
عملية التسرب المبينة في المواد.

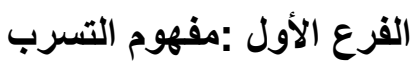

ولقد عرف المشرع الجزائري التسرب في نص المادة 65 مكرر 12 بأنه " يقصد

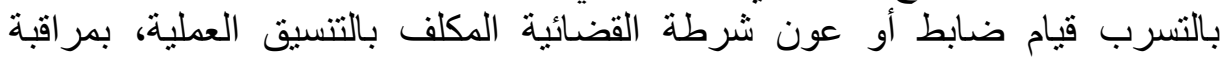
الأشخاص المشتبه في ارتكابهم جناية او جنحة بإيهامهم بأنه فاعل معهم".

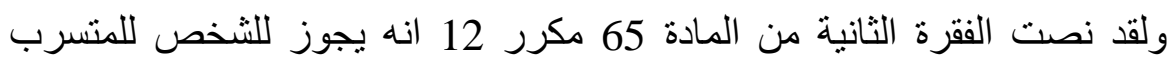

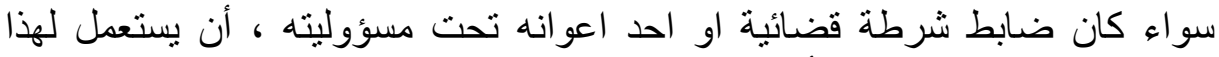

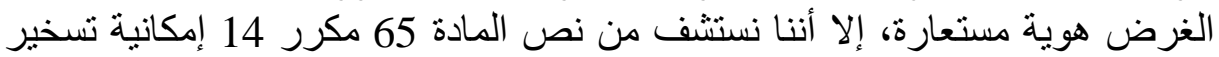
أثخاص أخريين للقيام أو المساعدة في إجراء أنساء التسرب.

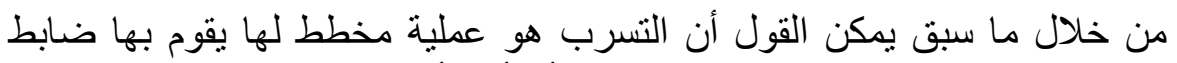
الثرطة القضائية ويتولى تنفيذها هو شخصيا أو أحد أعوانه تحت مسؤوليته لمراقبة التهبة

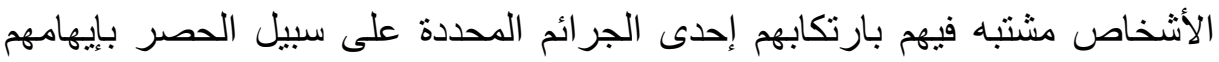


بعدة صور على انه فاعل معهم أو شريك لهم أو خاف، وهذا لمقتضيات وضرور ات ات بكن التحري والتحقيق، بعد استظهار إذن مسبق مكتوب من التواب الجهات القضائية وتحت رقابتهم وتباشر وفقا للشروط المحددة قانونا حسب ما نصت لـثن عليه المادة 65 مكرر 1.

نظر الأهمية هذه العملية في البحث والتحري عن الجرائم محددة، ونظرا لما لها لها

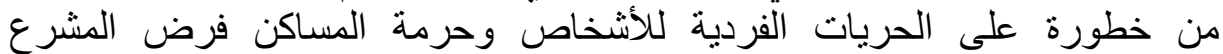

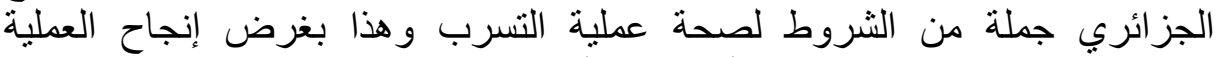

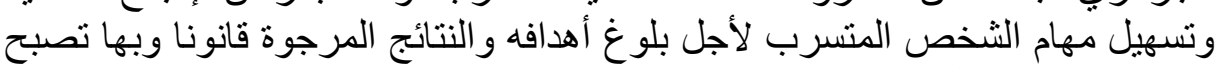
ذات شر عية وتتمثل فيما يلي (15): ـ أن تكون هنالك ضرورة للتحري أو التحقيق في إحدى الجرائم المحددة على سبيل

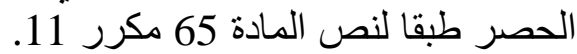

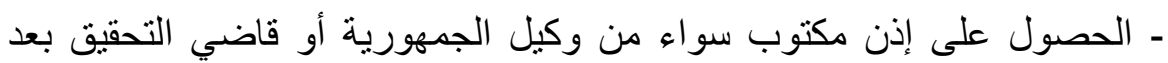

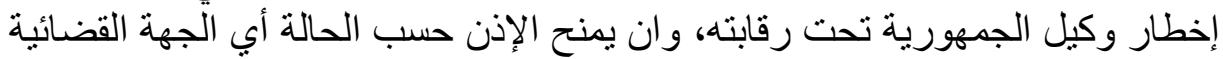
المانحة لها السلطة التقديرية في منحه طبقا للمادة 65 مكرر 11. - يجب أن يكون الإذن مسببا ومذكور فيه طبيعة الجريمة للجوء إلى هذا الإجراء

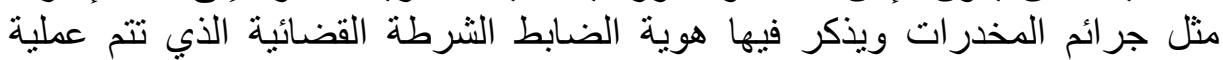
التسرب تحت مسؤوليته.

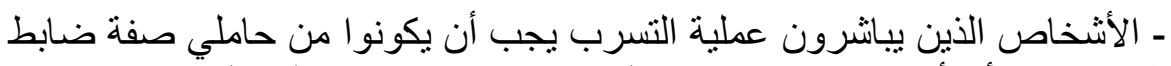
شرطة قضائية أو أعوانهم وتحت مسؤوليتهم و هذا ما نصت التبرت عليه المأدة 65 مكرر

الفرع الثاني :الأفعال التي يجوز للعون المتسرب ارتكابها

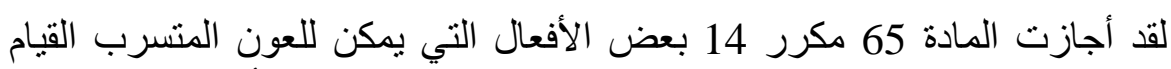

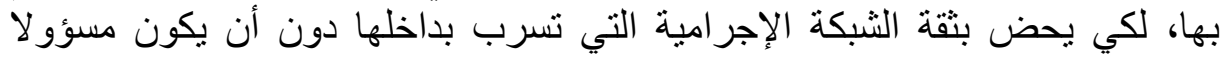

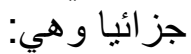

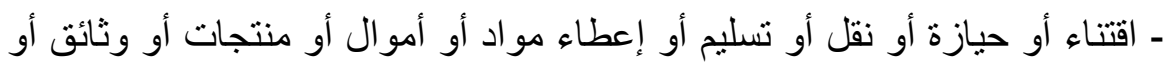

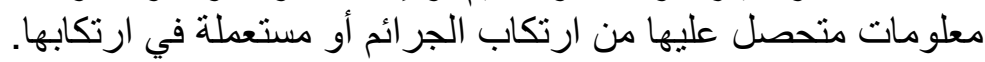

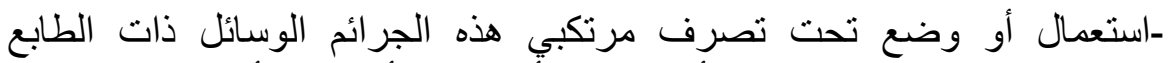

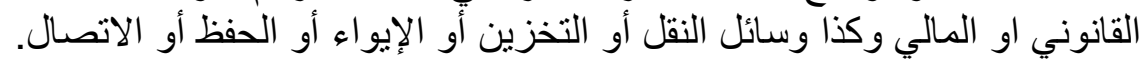

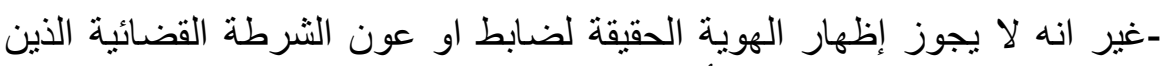

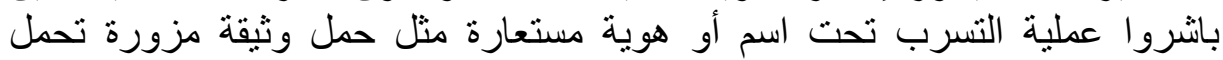
بيانات غير صحيحة من اجل إخفاء هويته الحقيقية في أي مرحلة من مراحل

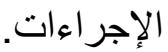

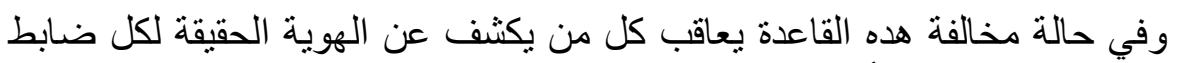

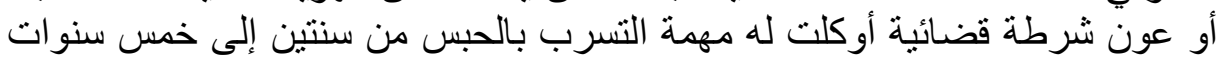

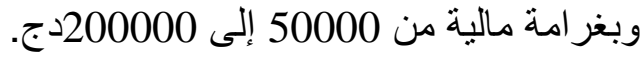

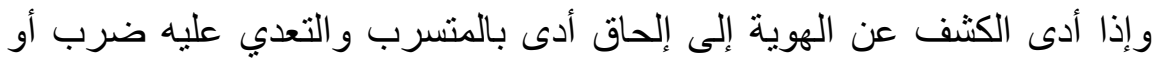

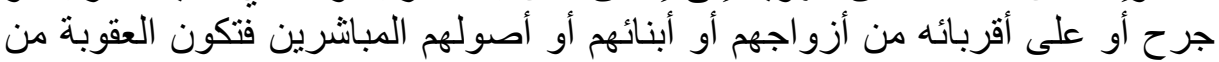

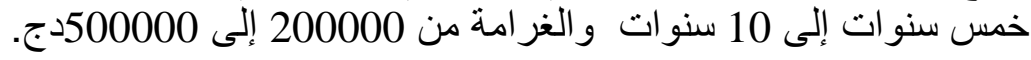

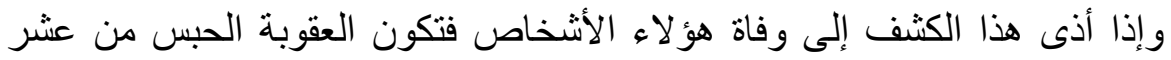

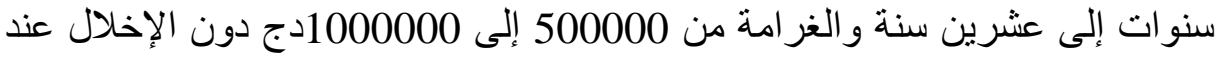


الاقتضاء بتطبيق الفصل الأول من الباب الثاني من الكتاب الثالث من قانون

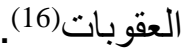

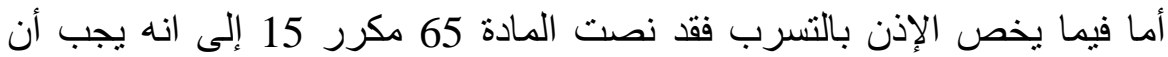

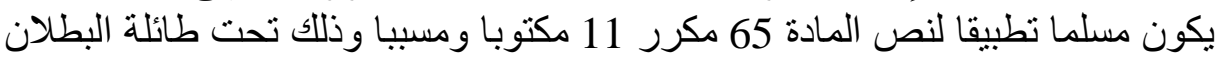
كما يجب أن يذكر في الإذن الجريمة التي تبرر اللجوء إلى هذا الإجر اء وهوية ضاءئ ضابط الثرطة القضائية الذي تتم العملية تحت مسؤوليته.

ويحدد هذا الإذن مدة عملية التسرب التي لا يمكن أن تتجاوز مدة 4 اشهر ويمكن

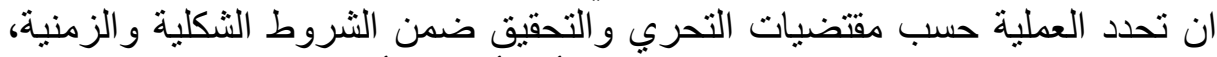
في حين يجوز للقاضي الذي رخص باجر اها، أن يأمر في أي وقت بوقفها قبل انقضاء

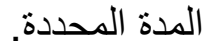

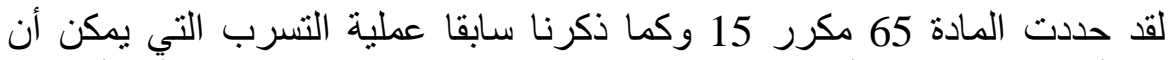

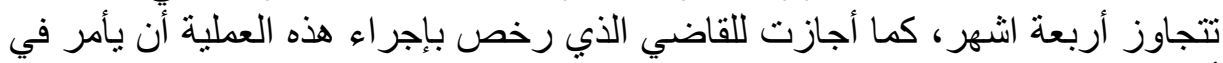
أي وقت بوقفها قبل انتهاء المدة المحددة.

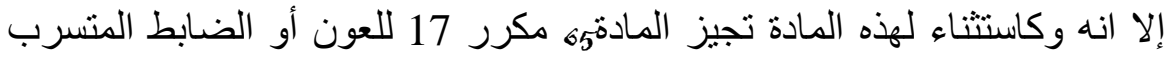

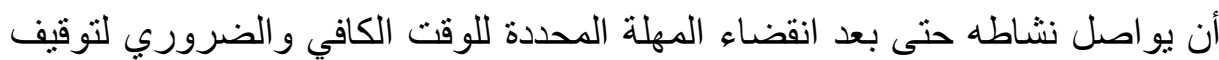

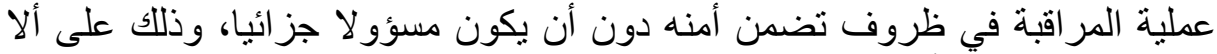
تتجاوز ذلك النشاط أربعة اثنهر فروفي

المطلب الثاني: اعتراض المرسلات وتسجيل الأصوات والتقاط الصور والتسليم المراقب

لقد جاء تعديل قانون الإجراءات الجزائية رقم 06-22 المؤرخ في 20 ديسمبر

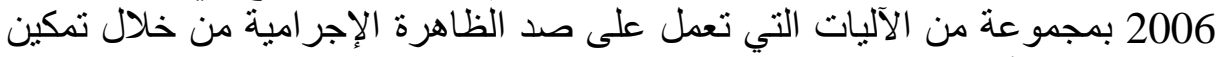

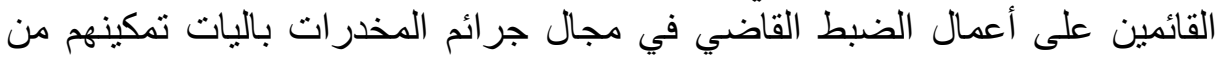

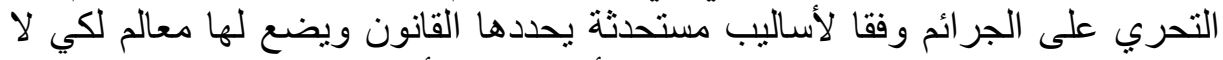

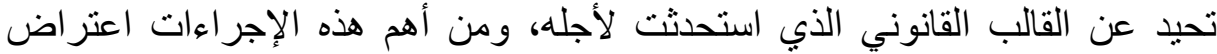

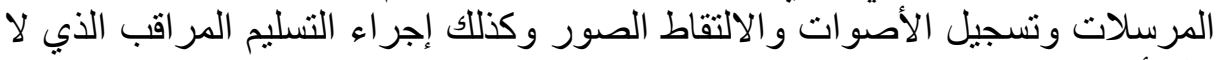

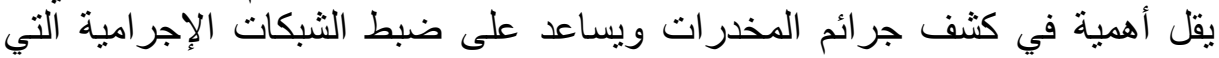

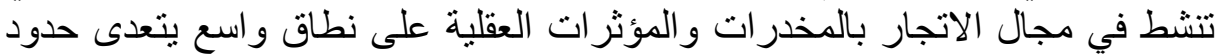

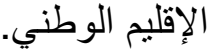

\section{الفرع الأول: اعتراض المرسلات وتسجيل الأصوات والتقاط الصور}

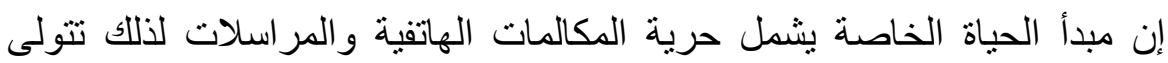

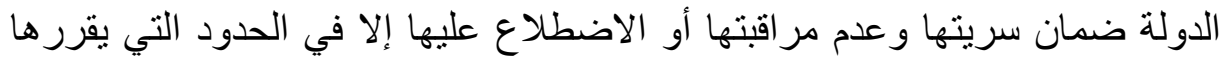

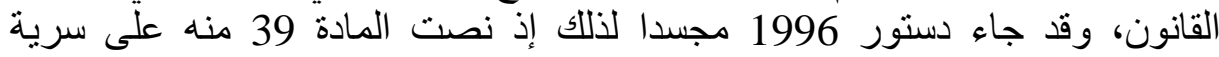
المر اسلات والاتصالات الخاصة بكل أشكالها.

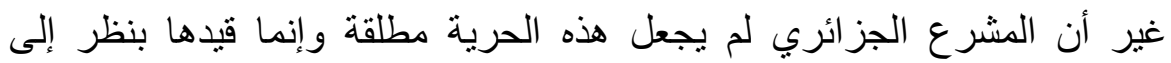

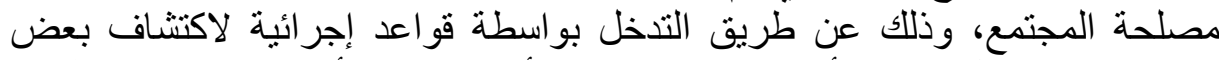

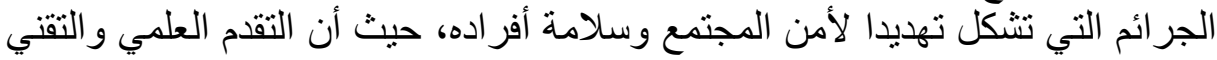

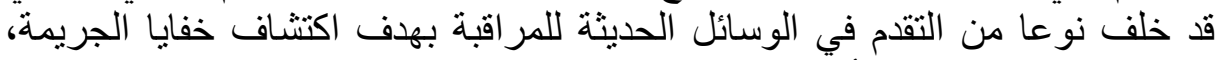

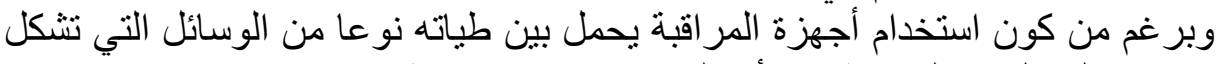

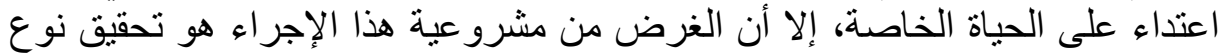


من التوازن بين حق الأفراد في الخصوصية والسرية وبين حق المجتمع في مكافحة

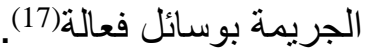

وقد نصت المادة 65 مكرر 05 من من القانون 06-22 المعدل لقانون الإجراءات

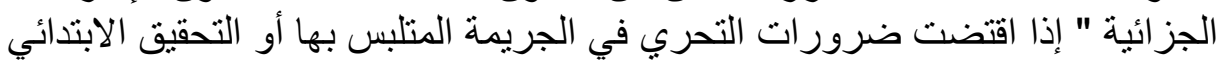

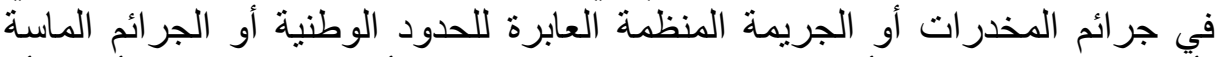

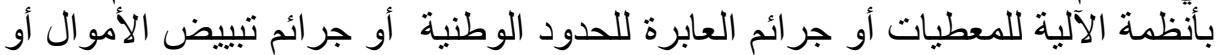

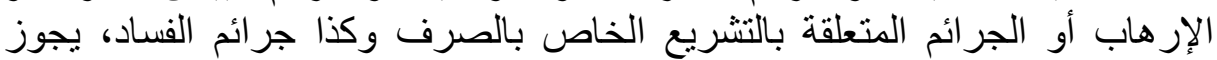

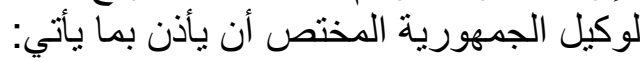
ـ اعتر اض المرسلات التي تتم عم طريق الاتصالات السلكية و اللاسلكية.

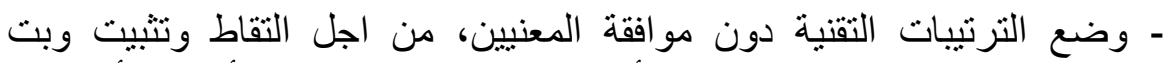

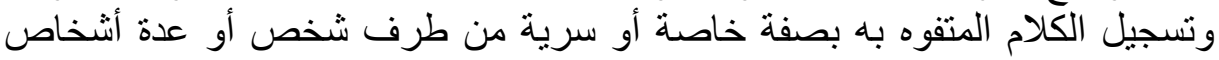

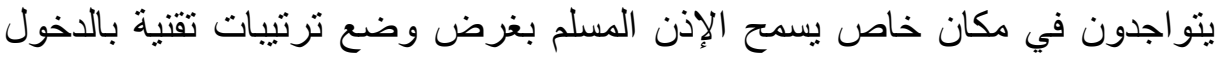

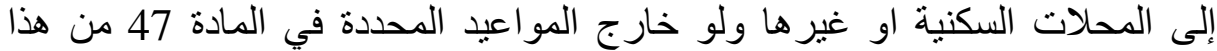
القانون وبغير علم أو رضا الأشخاص الذين لهم الحت الحق في تلك الأماكن. - تتفيذ العمليات المأذون بها على هذا الأساس تحت مراقبة المباثرة لوكيل

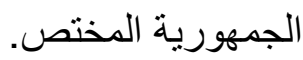
- في حالة فتح تحقيق قضائي، تتم العمليات المذكورة بناءا على إذن من قاضي التحقيق وتحت مر اقبته المباشرة.".

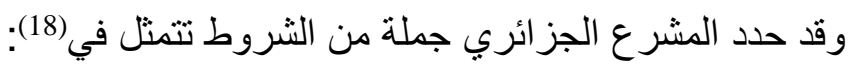
ـ أن يكون بصدد التحري في الجرائم المتلبس بها أو التحقيق الابتدائي في الجرائم الجرئ الخطيرة المحدة في المادة 56 مكرر 05 من قانون الإجر اءات الجزائية.

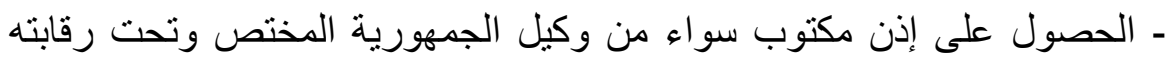

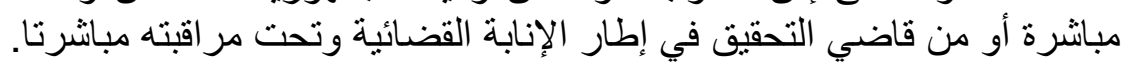
- يجب أن يتضمن الإذن المسموح على كل العناصر التي تسمح بالتعرف على الإنى الإنى

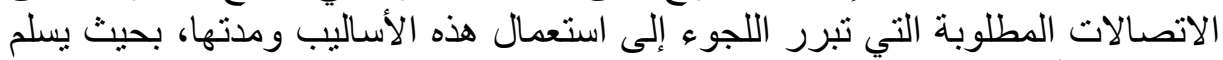

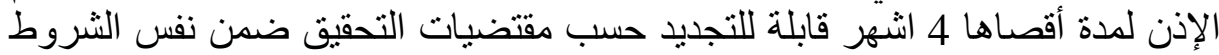
الثكلية والزمنية طبقا لنص المادة 65 مكرر 07. كما نصت المادة 65 مكرر 08 من قانون الإجراءات الجزائية على انه الهيه يجوز

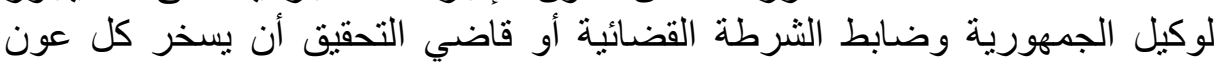

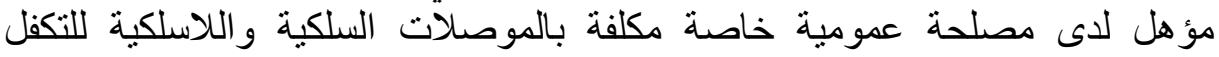
بالجو انب التقنية لهذه العملية.

ويجب على ضابط الثرطة القضائية المأذون له أو المناب أن يحرر محضر

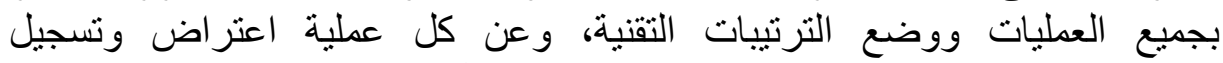

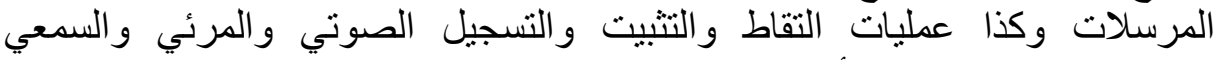

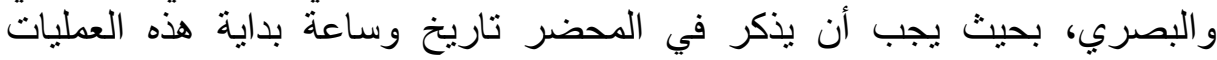

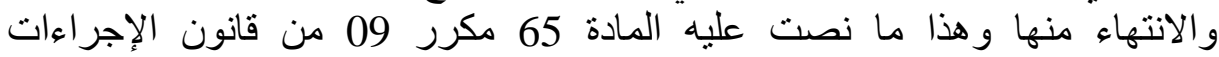

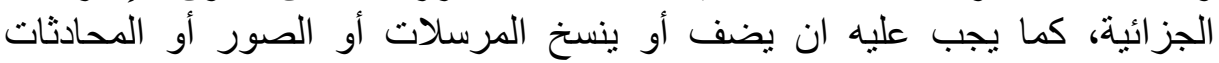

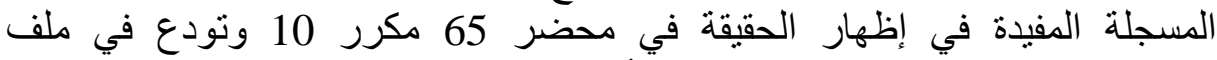

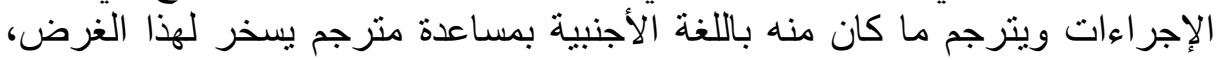
وينطبق عليها ما ينطبق على حجية المحاضر الضبط القئ القضائي. 
الفرع الثاني: التسليم المراقب

نظر لاختلاف جر ائم المخدرات عن بقية الجر ائم لاتساع حلقاتها المتسلسلة انطلاقا

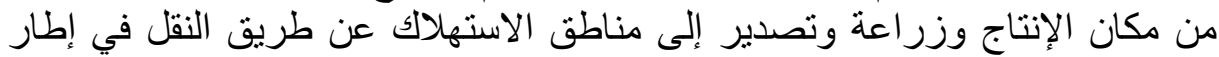

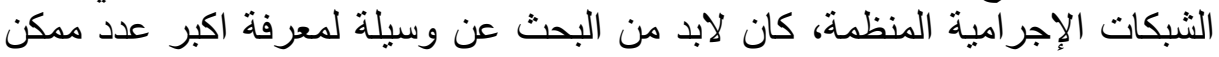

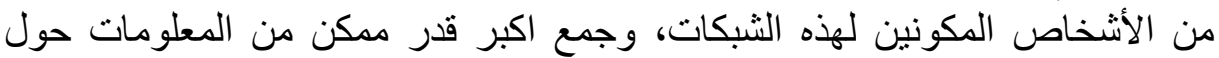

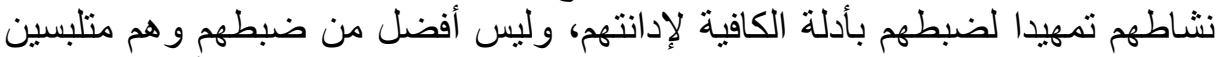

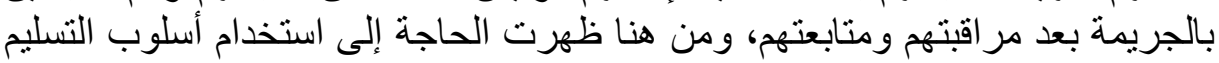

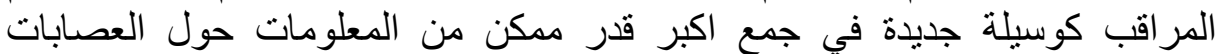

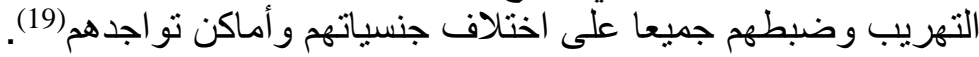

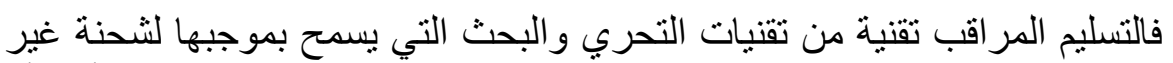

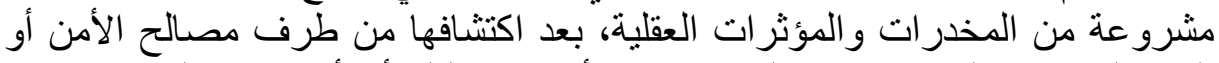

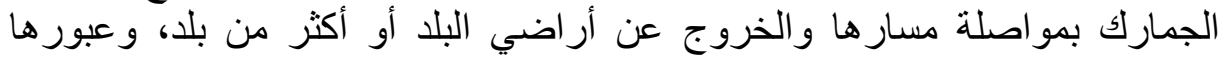

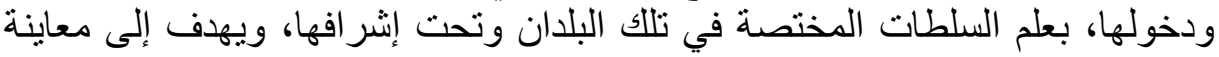

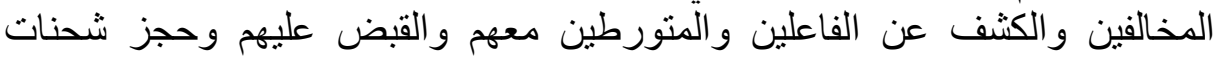
المخدر ات و المؤثر ات العقلية(20).

ولقد عرف المشرع الجزائري التسليم المر اقب في المادة 02 من قانون الوقاية من

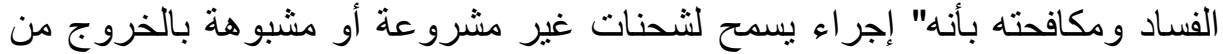

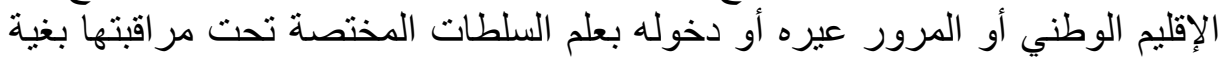

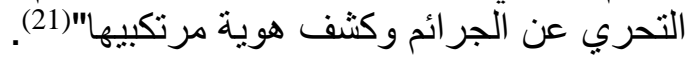

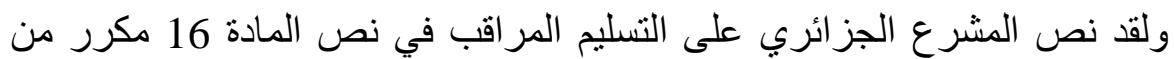

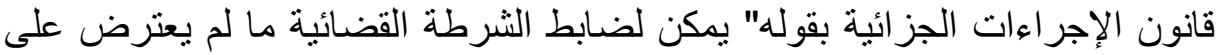

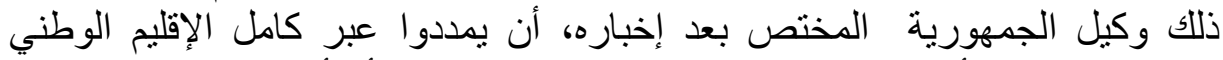

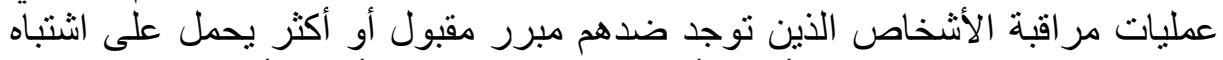

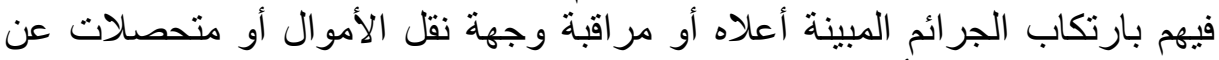

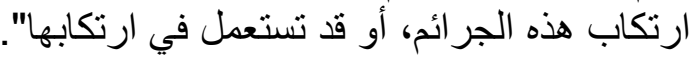

كما نصت على هذا الإجراء المادتين 02 و56 من قانون الوقاية من الفساد

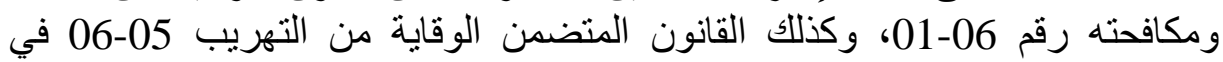

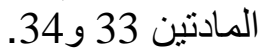

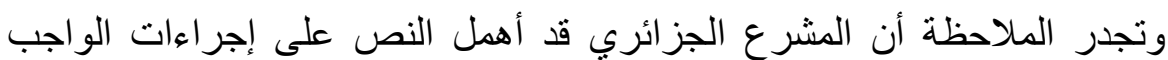

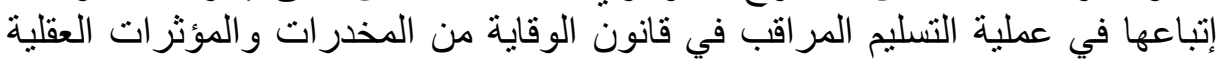

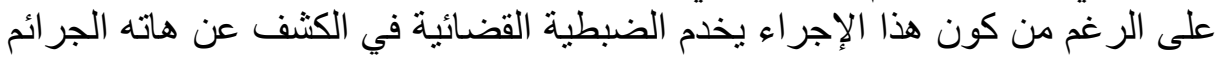

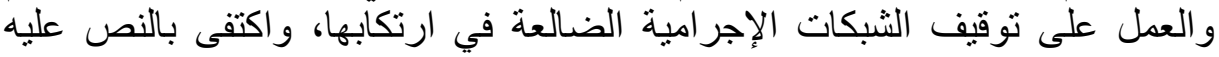

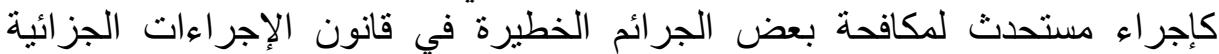
وقانون الوقاية من الفساد وقانون الوقاية من التهريب ومكافحته.

الخاتمة

من خلال تطرقنا لموضوع توسيع سلطات الثرطة القضائية في جر ائم المخدر ات

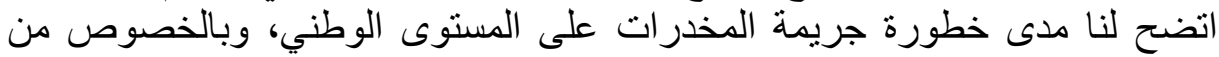

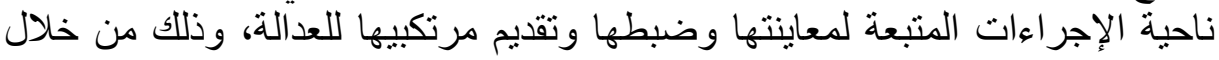
رسم سياسة إجرائية تمكن الجهات القائمة على الضبط القضائي من ممارسة مهامها 
في جو يكفل لها القيام بمجريات التحريات الأولية على الوجه المطلوب ولكن في إطار

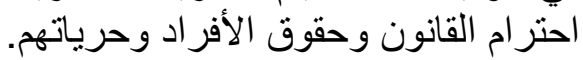

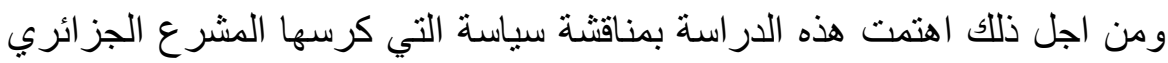

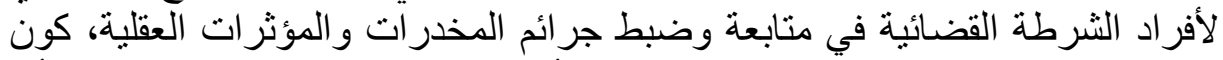

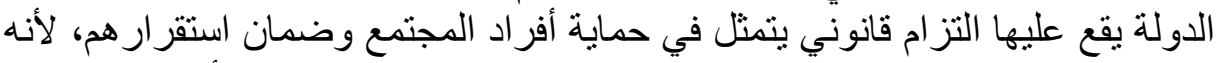

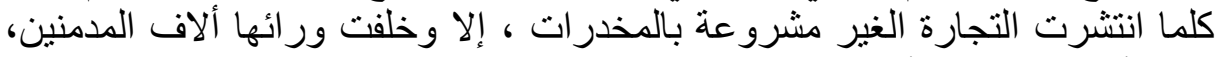

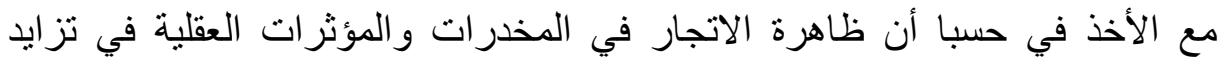

\section{- النتائج : -}

أما بالنسبة للنتائج التي توصلنا إليها من خلال دراستنا للإشكالية المطروحة حول

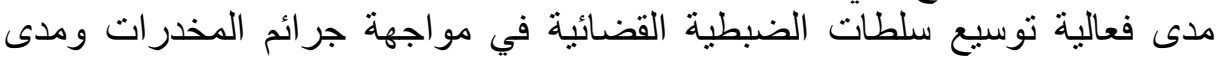

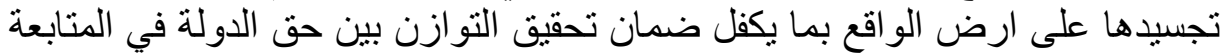

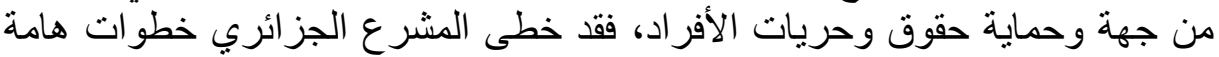

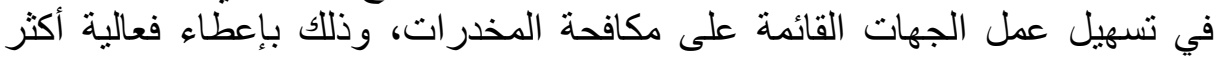

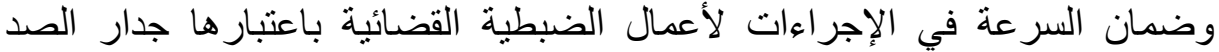

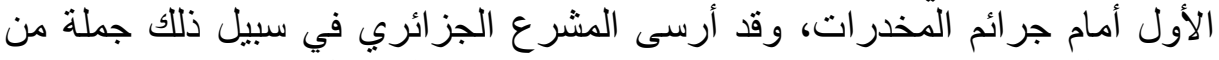

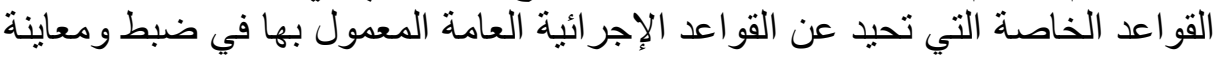

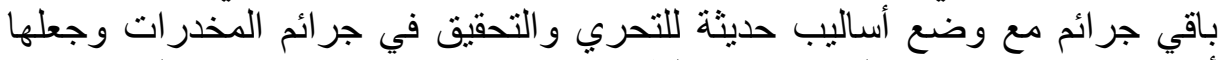
أكثر ملائمة واستجابة لخصوصية الظاهرة الإجرامية في مكافحتها والوالوفاية فنها

- وسعت من فئات الضبط القضائي لمعاينة وضبط جر ائم المخدرات حيث شملت

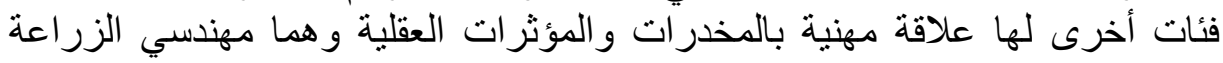

- توسيع الاختصاص الإقليمي للضبطية القضائية أثناء منابعة جرائم المخدرات

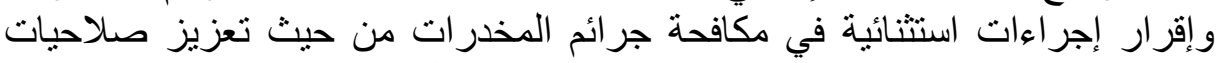

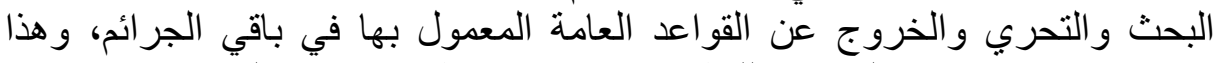
بخصوص تمديد مدة التوقيف للنظر، و واستحداث نظام خاص بالتفنتش في جرائم

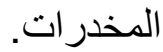

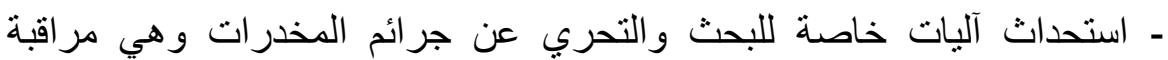

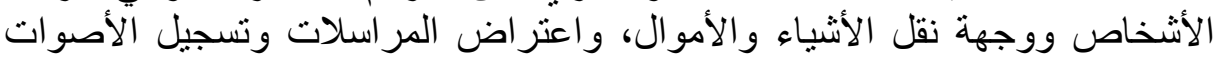

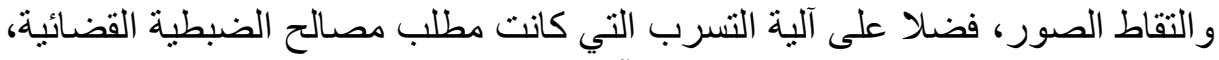

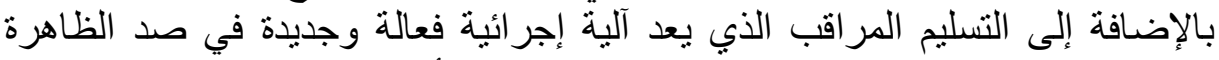

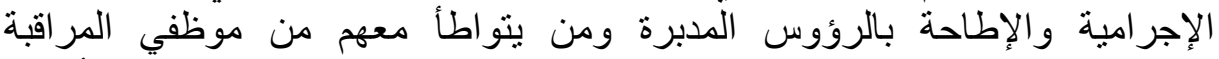

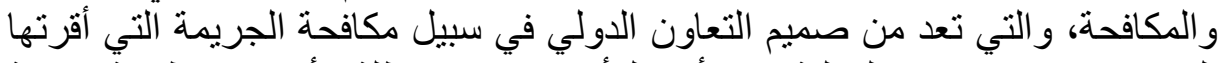

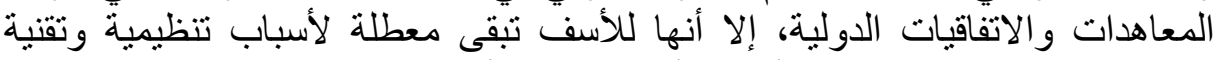

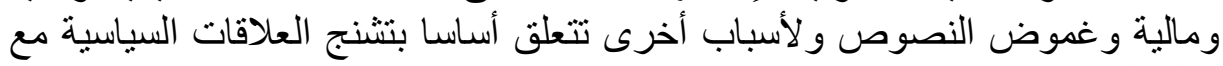
دول الجوار.

\section{ـ التوصيات والاقتراحات :}

- ينبغي أن تكون الإجراءات المتبعة أثناء مرحلة التحري وضبط جر ائم المخدرات و المؤثرات العقلية صحيحة وتستند للقانون، بما بكفل تحقيق التوازن التهان بين مصلحة 
الدولة في متابعة مرتكبي هذه الجرائم وتوقيع العقاب عليهم، ومصلحة الأفراد في ضمان حرياتهم وحقوقهم الشخصية.

- يجب أن ينص المشرع الجزائري صرحتا في قانون الوقاية من المخدرات إتهرئ

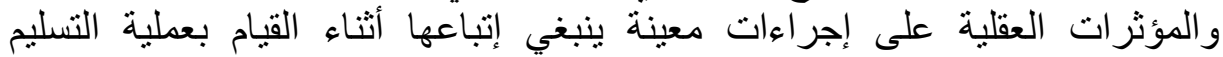

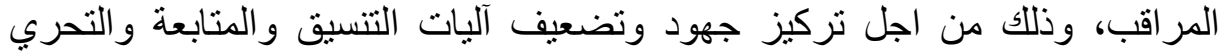

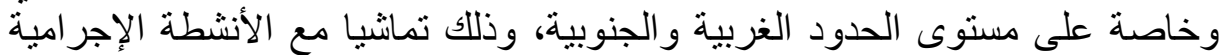

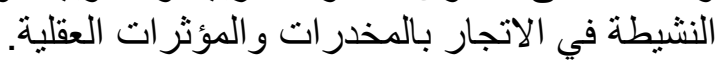

- ضرورة توفير الإمكانيات المادية والمالية اللازمة والحديثة للضبطية القضائية

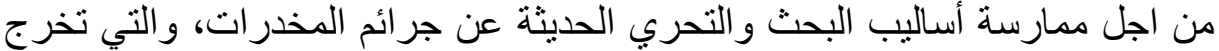
عن القواعد العامة وتمس بالحريات والحقوق الفردية كاعتر اض المرالت المرسلات والتقاط

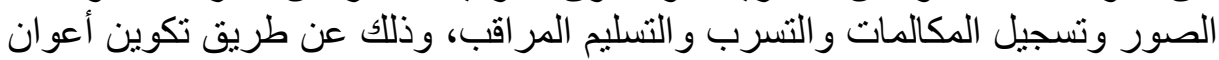

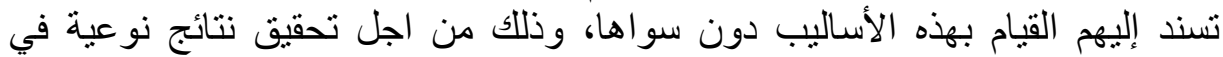
مجال القضاء على جر ائم الاتجار بالمخدرات و المؤثرات التهات العقلية.

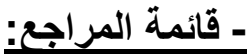

1- سليمان بارش: شرح قانون الإجراءات الجزائية الجزائري، دار الثهاب للطباعة

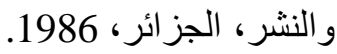

2- عبد الله أوهاييية: شرح قانون الإجراءات الجزائية الجزائري، دار هومة، الجزائر، .2008

3- أحمد غاي: ضمانات المشتبه فيه أثناء التحريات الأولية، دار هومة، الجزائر، .2003

4- بن كثير عيسى: الإجراءات الخاصة المطبقة على الإجرام الخطير، نشرة القضاة، العدد 36، ديوان المطبو عات التربوية، الجز ائر، 2008.

5- لحسين بن شيخ اث ملويا: مبادئ القانون الجزائي العام، الطبعة الثانية، دار هومة

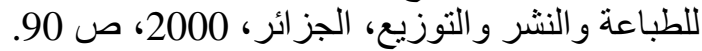

6- فضيل العيش: شرع قانون الإجراءات الجزائية بين النظري و التطبيق، مطبعة

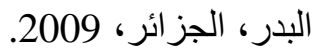

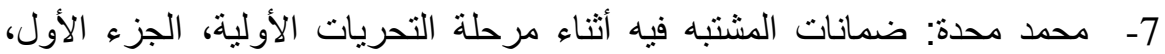
الطبعة الأولى، دار النهضة العربية، عين مليلة. الجزائر، 1991.

8- مروك نصر الدين: محاضرات في الاثباث الجنائي - النظرية العامة للاثباث

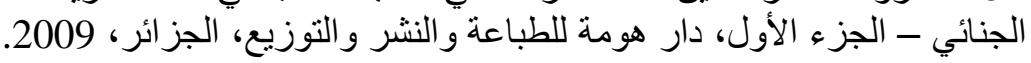

9- محمد حزيط: مذكرات في قانون الإجر اءات الجز ائية الجز ائري، الطبعة الثانية، دار

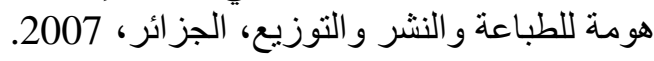
10- انظر في ذلك: المادة 65 مكرر 16 من قانون الإجر اءات الجزائية.

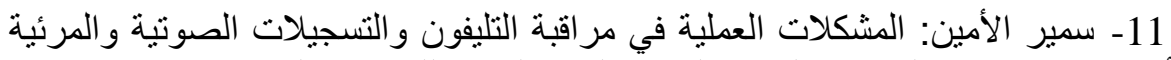
و أثر هما في الاثباث الجنائي، الطبعة الثانية، النسر الذهبية فئل للطباعة، القاهرة، 1998.

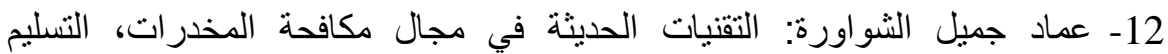
المر اقب، مجلة أكاديمية نايف العربية للعلوم الأمنية، مركز الدراسات والبحة البحوث، الرياض، 
13- صالح عبد النوري: التعاون الدولي في مجال التسليم المراقب، ، مجلة أكاديمية نايف العربية للعلوم الأمنية، مركز الدراسات و الّبحوث، الرياض، السعودية، 2002.

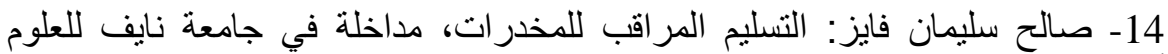
الأمنية، الرياض، السعودية، 2009.

15- Charel para: traite de procédure pénale policière, libraire Aristide quillet, paris, 2008.

$$
\text { 16- ق - قانون الاجر اءات الجز ائية. }
$$

17- قانون الوقاية من المخدرات و المؤثرات العقلية 04-18.

ـالهوامش:

1- سليمان بارش: شرح قانون الإجراءات الجزائية الجزائري، دار الثهاب للطباعة والنشر،

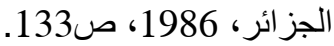

2- عبد الله أو هاييية: شرح قانون الإجراءات الجزائية الجزائري، دار هومة، الجزائر، 2008،

3- ل للإشارة انه تم اضافة شرط التأهيل حتى يتمكن ضباط الشرطة القضائية الممارسة الفعلية المهام المنوطة بهم بهده الصفة باستثناء رؤساء المجالس الشعبية عن طريق اضافة المادة 15 مكرر الى غاية المادة 15 مكرر2 التي تنظم اجر اء التأهيل بموجب القانون رقم : 17-07 المؤرخ في 27 مارس 2017 المعدل والمتمم لقانون الاجراءات وسرعان ما ترجع عن هذا الشرط بإلغاء هذه المواد بموجب التعديل: رقم 19-10 المؤرخ في 11ديسمبر 2019

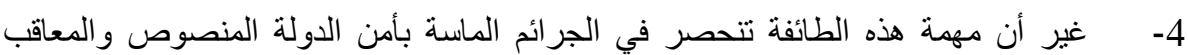

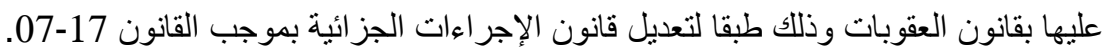

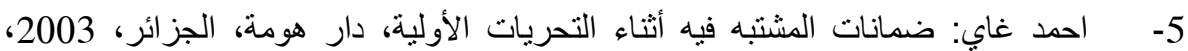

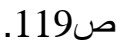

6- بن كثير عبسى: الإجراءات الخاصة المطبقة على الإجرام الخطير، نشرة القضاة، العدد 63، ديوان المطبو عات التربوية، الجزائر، 2008، ص86. 7- لحسين بن شيخ اث ملويا: مبادئ القانون الجزائي العام، الطبعة الثانية، دار هومة للطباعة

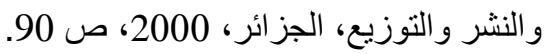
8- فضيل العيش: شرع قانون الإجراءات الجزائية بين النظري والتطبيق، مطبعة البدر،

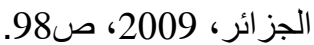

9- انظر: المادة 16 فقرة 6 من القانون 22-06 المعدل و المتمم لقانون الإجر اءات الجز ائية.

10- Charel para: traite de procédure pénale policière, libraire Aristide quillet, paris, p272.

11- محمد محدة: ضمانات المشتبه فيه أثناء مرحلة التحريات الأولية، الجزء الأول، الطبعة

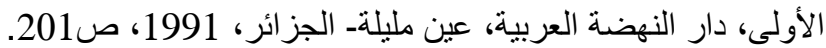

12- د. مروك نصر الدين: محاضرات في الاثباث الجنائي ـ النظرية العامة للاثباث الجنائي ـ الجزء الأول، دار هومة للطباعة والنشر والتوزيع، الجزائر، 2009، ص337.

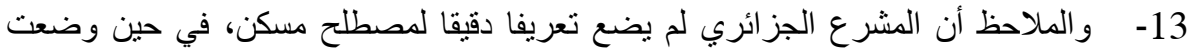

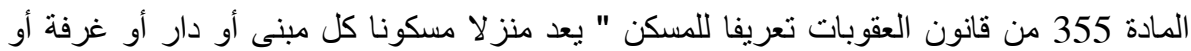

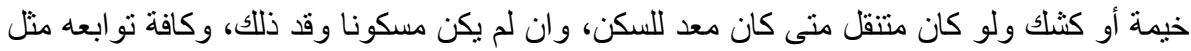


الاحواش وحظائر الدواجن ومخازن الغلال والإسطبلات والمباني التي توجد بداخلها مهما كان

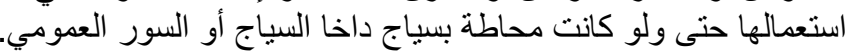

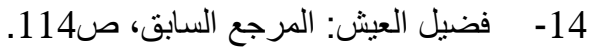

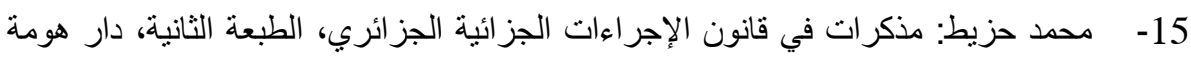

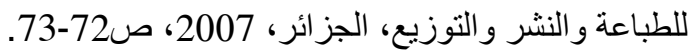

16- انظر في ذلك: المادة 65 مكرر 16 من قانون الإجر اءات الجزائية.

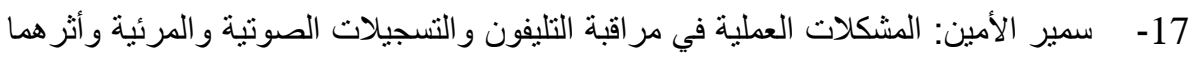

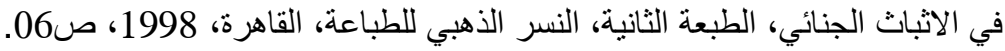

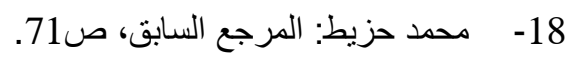

19- عماد جميل الثواورة: التقنيات الحديثة في مجال مكافحة المخدرات، التسليم المر اقب، مجلة أكاديمية نايف العربية للعلوم الأمنية، مركز الدراسات والبحوث، الرياض، السعودية، 2002،

20- صالح عبد النوري: التعاون الدولي في مجال التسليم المراقب، ، مجلة أكاديمية نايف

العربية للعلوم الأمنبة، مركز الدراسات والبحوث، الرياض، السعودية، 2002، ص13.

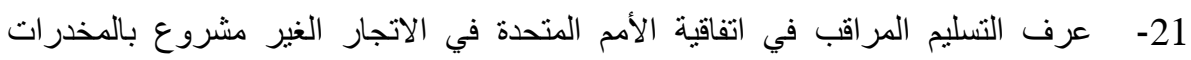

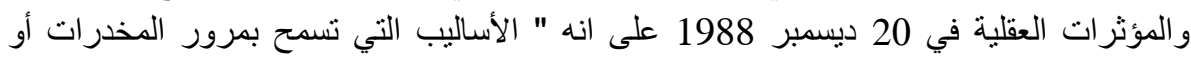

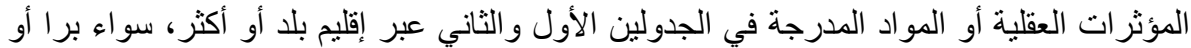

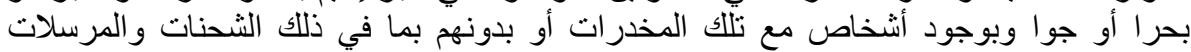

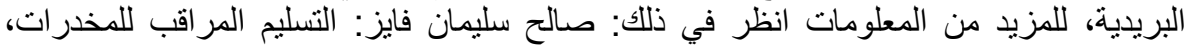

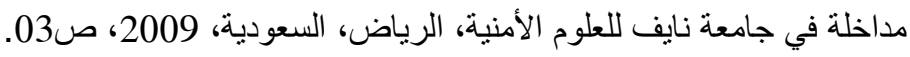

